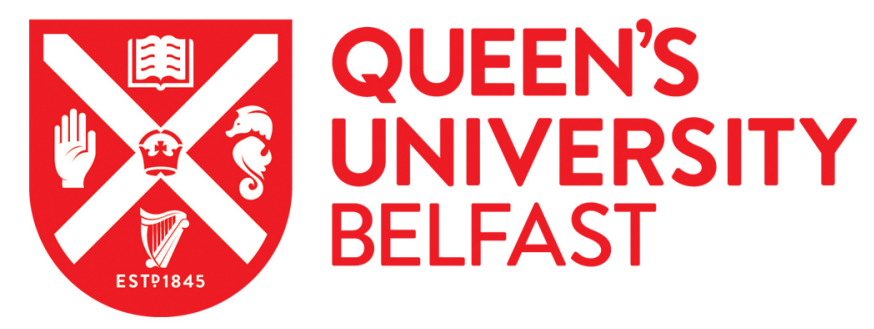

\title{
Identification and bisection of temporal durations and tone frequencies: Common models for temporal and non-temporal stimuli.
} Brown, G. D. A., McCormack, T., Smith, M., \& Stewart, N. (2005). Identification and bisection of temporal
durations and tone frequencies: Common models for temporal and non-temporal stimuli. Journal of Experimental
Psychology Human Perception and Performance, 31 (5)(5), 919-938. https://doi.org/10.1037/00961523.31.5.919

Published in:

Journal of Experimental Psychology Human Perception and Performance

Document Version:

Early version, also known as pre-print

Queen's University Belfast - Research Portal:

Link to publication record in Queen's University Belfast Research Portal

\footnotetext{
General rights

Copyright for the publications made accessible via the Queen's University Belfast Research Portal is retained by the author(s) and / or other copyright owners and it is a condition of accessing these publications that users recognise and abide by the legal requirements associated with these rights.
}

Take down policy

The Research Portal is Queen's institutional repository that provides access to Queen's research output. Every effort has been made to ensure that content in the Research Portal does not infringe any person's rights, or applicable UK laws. If you discover content in the Research Portal that you believe breaches copyright or violates any law, please contact openaccess@qub.ac.uk. 


\title{
Identification and Bisection of Temporal Durations and Tone Frequencies: Common Models for Temporal and Nontemporal Stimuli
}

\author{
Gordon D. A. Brown \\ University of Warwick
}

\author{
Teresa McCormack \\ Queen's University Belfast
}

\author{
Mark Smith and Neil Stewart \\ University of Warwick
}

\begin{abstract}
Two experiments examined identification and bisection of tones varying in temporal duration (Experiment 1) or frequency (Experiment 2). Absolute identification of both durations and frequencies was influenced by prior stimuli and by stimulus distribution. Stimulus distribution influenced bisection for both stimulus types consistently, with more positively skewed distributions producing lower bisection points. The effect of distribution was greater when the ratio of the largest to smallest stimulus magnitude was greater. A simple mathematical model, temporal range frequency theory, was applied. It is concluded that (a) similar principles describe identification of temporal durations and other stimulus dimensions and (b) temporal bisection point shifts can be understood in terms of psychophysical principles independently developed in nontemporal domains, such as A. Parducci's (1965) range frequency theory.
\end{abstract}

Keywords: temporal bisection, range frequency theory, duration, timing, identification

This paper addresses two questions. At a general level, our concern is with whether human identification and discrimination of short temporal durations can be described in terms of the same principles that are known to characterize identification and discrimination of other simple perceptual stimuli (e.g., weights, degrees of loudness, or line lengths). Is a unified account possible? Recent models of timing have been developed independently from earlier traditions of modeling of perceptual identification and discrimination; here in contrast we argue that similar principles may apply in both cases. A second, more specific issue addressed in this paper concerns shifts in the temporal bisection point (the duration that is equally likely to be judged the same as the shortest or longest magnitude in a stimulus set). Several models of timing have proposed accounts of bisection point shifts that are specific to temporal processing; here we argue that a more general account of bisection point shifts can be given in terms of a model developed outside the temporal domain: range frequency theory (RFT; e.g., Parducci, 1965, 1995). The predictions of this claim are explored with a simple mathematical model, which we term temporal range frequency theory (TRFT), and tested in two experiments.

Gordon D. A. Brown, Mark Smith, and Neil Stewart, Department of Psychology, University of Warwick, Coventry, United Kingdom; Teresa McCormack, School of Psychology, Queen's University Belfast, Belfast, Northern Ireland, United Kingdom.

This research was supported by Economic and Social Research Council (ESRC) Grant R000239351 awarded to Gordon D. A. Brown and others; ESRC Grant R000239002 awarded to Teresa McCormack, Gordon D. A. Brown, and John H. Wearden; and Biotechnology and Biological Sciences Research Council Grant 88/S15050 awarded to Gordon D. A. Brown and Teresa McCormack. We are grateful to John H. Wearden for useful discussion on many occasions.

Correspondence concerning this article should be addressed to Gordon D. A. Brown, Department of Psychology, University of Warwick, Coventry CV4 7AL, United Kingdom. E-mail: g.d.a.brown@warwick.ac.uk
Models of Timing

Over the past decade, understanding of human timing has been advanced through the use of temporal generalization and temporal bisection tasks. In the temporal generalization task, participants are exposed to a standard stimulus of a fixed duration. They then judge whether or not subsequently presented stimuli are of the same duration as the standard. Here we focus on temporal bisection tasks, a variety of which have been developed for use with human adults and children (Allan, 2002a, 2002b; Allan \& Gerhardt, 2001; Allan \& Gibbon, 1991; Droit-Volet, Clement, \& Fayol, 2003; Droit-Volet \& Wearden, 2001, 2002; Gautier \& Droit-Volet, 2002; Gibbon, 1981; McCormack, Brown, Maylor, Darby, \& Green, 1999; Penney, Gibbon, \& Meck, 2000; Rattat \& Droit-Volet, 2001; Rodriguez-Girones \& Kacelnik, 2001; Wearden, 1991; Wearden \& Bray, 2001; Wearden \& Ferrara, 1995, 1996; Wearden, Rogers, \& Thomas, 1997) based on adaptation of tasks originally used with animals (e.g., Church \& Deluty, 1977; Gibbon, 1981, 1986; Machado \& Keen, 2003; Platt \& Davis, 1983; Raslear, 1983, 1985; Siegel, 1986; Siegel \& Church, 1984). In a typical temporal bisection task, participants initially receive two standard durations, one long and one short. They then judge whether subsequently presented durations are more similar to the long or the short standard. Various versions of such tasks have been employed, allowing manipulation of factors such as the memory demands of the task (e.g., Allan, 2002a; Rodriguez-Girones \& Kacelnik, 2001; Wearden \& Bray, 2001) or the number of times a given duration is repeated within an experiment (e.g., Allan \& Gerhardt, 2001). The stimulus durations that are employed are typically short enough (less than 1 or $2 \mathrm{~s}$ ) to prevent chronometric counting. These tasks generally produce consistent and orderly data in humans across a wide age range, although, as we show below, a complete account of some of the results is lacking. 
A variety of models have been developed to account for the results of temporal bisection and generalization tasks. Scalar expectancy theory (SET) has been particularly influential in both the human and animal literature, although other perspectives are available (e.g., Block \& Zakay, 1997; Dragoi, Staddon, Palmer, \& Buhusi, 2003; Killeen \& Fetterman, 1988; Killeen \& Taylor, 2000; Machado, 1997; Machado \& Guilhardi, 2000; Machado \& Keen, 1999; McCormack et al., 1999; McCormack, Brown, Maylor, Richardson, \& Darby, 2002; Staddon \& Higa, 1999). According to SET, timing-behavior is based on the output of an internal clock that provides memory representations that can be retrieved and compared with a current temporal interval (e.g., Allan \& Gibbon, 1991; Gibbon, Church, \& Meck, 1984; Wearden, 1991, 1992, 1995; Wearden \& Ferrara, 1995, 1996). A more detailed discussion of SET and its relation to the account we develop here is given in the General Discussion.

\section{Judgment and Identification of Nontemporal Stimuli}

A number of modifications to SET have been proposed to account for the detailed pattern of empirical findings. Here we focus on the relation between the temporal bisection and identification tasks that have motivated SET, and we introduce more general psychophysical models that have been developed independently to account for identification and discrimination of other perceptual dimensions. First, we note that commonly used duration-judgment tasks are in many respects akin to identification tasks that have been carried out using a number of perceptual dimensions including weight, line length, and brightness (Berliner \& Durlach, 1973; Bower, 1971; Miller, 1956; Murdock, 1960; Pollack, 1952). A typical absolute identification task proceeds as follows. Stimuli that vary along a single dimension (e.g., a series of lines varying in length from short to long) are shown to participants in the first phase of an experiment. Each item in the stimulus set is assigned a number representing its place in the series (e.g., in an eight-stimulus set, the item with the smallest magnitude is labeled " 1 " and the item with largest magnitude is labeled "8," although arbitrary nonordered labels may also be used). In the main part of the experiment, individual items are presented to participants who must respond with the appropriate number for that item. Magnitude-judgment tasks are similar in that responses to presented items must be based on the perceived magnitude of the stimuli, but they differ in that a constrained set of stimuli need not be used and feedback is not provided.

It is evident that there are similarities between identification and judgment tasks and the bisection and generalization tasks typically used to investigate timing. In both cases, responses must be made to unidimensionally varying stimuli based on their position along the dimension. In both absolute identification and temporal generalization, participants must judge whether a presented item is the same or different from an item or items presented earlier. The temporal bisection task is usually described as one in which various test items are judged in terms of their similarity to each of two previously presented items.

The similarities between timing tasks and other widely used identification tasks is of theoretical interest because of the possibility that temporal duration and other dimensions (such as line length or loudness) may be processed in similar ways, and hence that models developed to account for absolute identification performance and magnitude judgments over the past 40 years may be relevant to understanding timing-behavior (e.g., McCormack et al., 2002). A wide variety of models of absolute identification have been developed (e.g., Berliner \& Durlach, 1973; Lacouture, 1997; Lacouture \& Marley, 1991, 1995; Laming, 1984; Luce, Nosofsky, Green, \& Smith, 1982; Nosofsky, 1997; Stewart, Brown, \& Chater, in press; Treisman, 1985; Treisman \& Williams, 1984). Although there are several differences between these models, we emphasize two key points of contrast between models of judgment and identification, and most models of timing. The first of these points we refer to as distribution dependence. The distribution dependence principle states that responses to a given item will not only depend on the relation between that item and its representation in memory, but will be influenced by the entire distribution of contextual stimuli. For example, the information transmitted in an absolute identification seems to be limited to two to three bits for unidimensional stimuli (Garner, 1953, 1962; Laming, 1984; Miller, 1956; Pollack, 1952). This is equivalent to perfect classification of about five items. Crucially, increasing the separation between adjacent stimuli beyond the point at which pairs of stimuli are perfectly discriminable when presented in isolation does not substantially increase information transmission (Braida \& Durlach, 1972; Pollack, 1952), indicating that the identifiability of an item is normally limited not primarily by perceptual factors but instead by the item's location relative to a set of other stimuli. In magnitude estimation tasks, the judged magnitude of a given item is strongly influenced by the skew of the distribution of other stimulus magnitudes within the set to be judged (e.g., Parducci, 1968, 1995). Some extant results are consistent with some distribution dependence in timing (e.g., Allan, 2002b; Penney, Allan, Meck, \& Gibbon, 1998; Wearden \& Ferrara, 1995, 1996; Wearden et al. 1997). Two key aims of this paper are (a) to test the prediction that much larger distribution dependence can be seen in temporal judgments and (b) to develop an explicit model.

The second major difference between SET-based approaches and nontemporal models concerns sequential effects. Most models of identification predict that the perception of the identity of a given item will be influenced in consistent ways by the identity of items presented on immediately preceding trials (e.g., Stewart et al., in press; Treisman \& Williams, 1984). These sequential effects, such as the assimilation of responses on trial $n$ to stimuli on trial $n-1$, are widely observed in the data (e.g., Garner, 1953 Holland \& Lockhead, 1968; Long, 1937; Ward \& Lockhead, 1970, 1971). Assimilation to previous trials is a general phenomenon that is also observed in judgments of relative intensity (Lockhead \& King, 1983), magnitude estimation (e.g., Jesteadt, Luce, \& Green, 1977) and matching (Stevens, 1975). Contrast effects are typically observed relative to trials more than one trial further back in the sequence (e.g., Ward \& Lockhead, 1970). Further evidence for the importance of sequential effects in simple perceptual identification is given by the observation that performance is higher when the sequence of presentation is constrained in such a way that the stimulus in each trial is relatively similar to the item in the previous trial (Luce et al., 1982; Nosofsky, 1983).

If the perception and identification of temporal durations is similar to perception and identification of other unidimensionally varying stimuli, strong sequential effects should be observed in absolute identification of durations. This paper tests this prediction. It also tests the following prediction: that the strong serial position effects that are observed in absolute identification of nontemporal stimuli, such that items near the end of the series are 
more accurately identified (e.g., Braida \& Durlach, 1972; Lacouture, 1997; Lacouture \& Marley, 1995; Murdock, 1960), will also be observed when temporal durations must be identified (see also Lacouture, Grondin, \& Mori, 2001). We now turn to findings that have been investigated primarily in the timing literature, findings that have received relatively little attention within more traditional research on nontemporal stimuli.

\section{Shifts in Bisection Point}

A phenomenon that has received considerable attention in the timing literature has been the location of the bisection point. In temporal bisection tasks, attention is typically given to the length of the duration that is equally likely to be judged as similar to (or identified with) the longest as the shortest duration. More specifically, bisection at the geometric mean (GM) is observed under some experimental conditions, while arithmetic mean (AM) bisection is observed under different experimental conditions. For example, consider a temporal bisection task in which the short standard is $200 \mathrm{~ms}$ and the long standard is $800 \mathrm{~ms}$. Assume that participants are exposed to seven experimental durations (200, $300,400,500,600,700$, and $800 \mathrm{~ms}$ ). For each experimental duration, the overall probability that it will be judged as more similar to the long standard is calculated. Characteristic S-shaped curves of the type seen in Figure 1 are found, such that the probability of responding "long" increases with the duration of the experimental item. The bisection point is calculated (either by curve fitting or simple linear extrapolation) as the point at which this probability is exactly .5. The temporal bisection points typically vary between the GM of the short and long standards (400 $\mathrm{ms})$ and the AM $(500 \mathrm{~ms})$. The location of the bisection point appears to vary systematically with experimental conditions, although clear conclusions are difficult to draw from the existing literature because the AM and GM are typically very close to one another, especially when the ratio between the long and the short standard is small.

More specifically, GM bisection is typically observed in rats (e.g., Church \& Deluty, 1977; Gibbon, 1981, 1986), albeit with some exceptions (see Wearden \& Ferrara, 1996, for a review). In

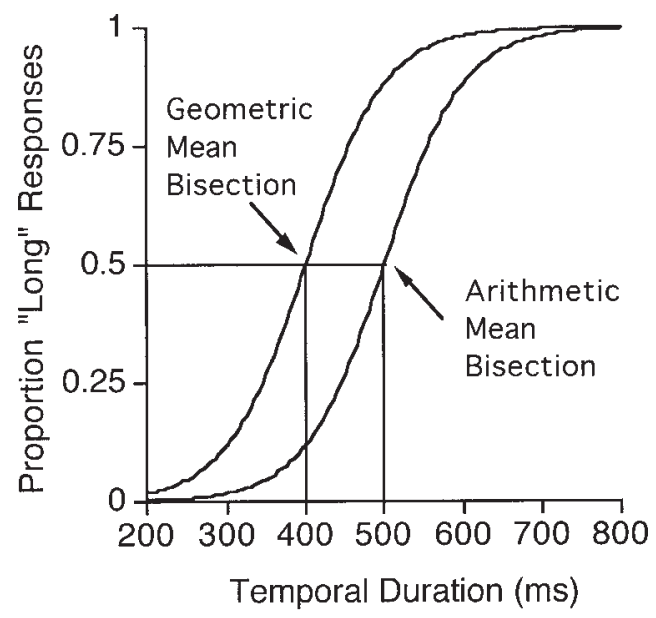

Figure 1. Temporal bisection curves illustrating geometric mean bisection and arithmetic mean bisection. humans, the location of the bisection point seems to depend on the distribution of the stimuli and on the long:short ratio. Allan and Gibbon (1991) found near-GM bisection when the long:short ratio was small and stimuli were arithmetically spaced (Experiment 1) or logarithmically spaced (Experiment 2). Wearden and Ferrara (1996) suggested that AM bisection is more likely when the long:short ratio is large and also concluded that stimulus distribution is influential only when the ratio is large (see also Allan, 2002b; Penney et al., 1998). Wearden and Ferrara (1995) found that the bisection point moved leftward (i.e., in the direction of the GM) if items were logarithmically rather than linearly spaced, as did Allan (2002b) and Penney et al. (1998), and suggested that time value judgments were context dependent (see also Wearden et al., 1997).

Although the overall pattern of results is far from clear, a possible generalization is that GM bisection is more likely to be obtained with logarithmically spaced stimuli, AM bisection is more likely to be obtained with arithmetically spaced stimuli, and that these effects are moderated by the long:short ratio such that distribution effects are greater when this ratio is large (Allan, 2002b; Penney et al., 1998; Wearden \& Ferrara, 1995, 1996). Rather than explore possible exceptions to this generalization (e.g., Wearden \& Ferrara, 1996; Wearden et al., 1997) in detail, we next consider independent theoretical motivation for the claim prior to experimental testing using more extreme stimulus distributions in order to permit a clearer assessment of the effect of long:short ratio and stimulus distribution on bisection point.

\section{Range Frequency Theory}

Is previous research on magnitude estimation relevant to understanding the pattern of results concerning shifts in the temporal bisection point? The application of independently motivated models of judgment to the temporal bisection paradigm might pave the way for a deeper theoretical understanding of changes in bisection point as a function of experimental conditions. Here we argue that just such an account is possible through application of the principles of RFT as developed by Parducci and his colleagues (Parducci, 1965, 1968, 1995).

RFT was designed to account for the subjective magnitudes that participants report for unidimensionally varying stimuli such as weights, line lengths, degrees of loudness, or tones varying in frequency. A particular focus is on the effects of the distribution of stimuli within the sets to be judged. Earlier accounts of magnitude estimation tasks included adaptation level theory (ALT; Helson, 1964) and range theory (Volkmann, 1951). According to ALT, the magnitude judgment for a given item will depend on the distance of that item from some weighted mean of the stimuli to be judged. Range theory, in contrast, states that the judgment given to a particular item will be determined at least partly by the position occupied by that item in relation to the two endpoints of that range, thus accommodating ALT's failure to account for effects of the variance of a set of stimulus magnitudes on the rating assigned to a particular stimulus magnitude. However, RFT was motivated by the observation that an item's ordinal position within the set to be judged also influences its rating. Consider two distributions of stimulus magnitudes as shown in Figure 2. The mean and endpoints of distributions $A$ and $B$ are identical. Furthermore, the positions of stimuli $X$ and $Y$ with respect to the endpoints of the distribution are identical in each case (being one third and two 


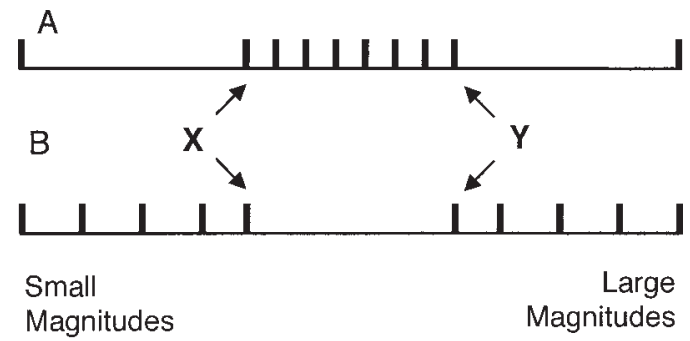

Figure 2. Two distributions of stimulus magnitudes to illustrate predictions of range frequency theory. $\mathrm{A}=$ unimodal distribution; $\mathrm{B}=$ bimodal distribution; $\mathrm{X}$ and $\mathrm{Y}=$ common points.

thirds up the stimulus range respectively). Therefore, according to both ALT and range theory, the magnitude estimations of $X$ and $Y$ will be the same for each distribution. However, as intuition suggests, and Parducci (1968) and others have confirmed, stimulus $X$ will be assigned a lower rating in distribution $A$ than in distribution $B$, while the reverse will be the case for stimulus $Y$. In intuitive terms, the observation is that participants "stretch out" their response scale in relatively crowded regions of stimulus space (see also Krumhansl, 1978). The RFT model (see Parducci, 1995, for a review) incorporates the empirical observations that the rating assigned to a given stimulus is determined both by its position within the range and its ordinal position within the ordered set of stimuli.

This can be formalized as follows (see, e.g., Parducci, 1995). Assume an ordered set of $n$ contextual stimuli: $\left\{x_{1}, x_{2}, \ldots, x_{i}, \ldots\right.$, $\left.x_{n}\right\}$. Then, if $M_{i}$ is the subjective psychological magnitude of $x_{i}$, it is given by

$$
M_{i}=w R_{i}+(1-w) F_{i},
$$

where $R_{i}$ is the range value of stimulus $i\left(S_{i}\right)$,

$$
R_{i}=\frac{S_{i}-x_{1}}{x_{n}-x_{1}},
$$

and $F_{i}$ is the frequency value, or ranked ordinal position of $S_{i}$, in the ordered set,

$$
F_{i}=\frac{i-1}{n-1}
$$

where $w$ is a weighting parameter that is often empirically estimated at about .5. In intuitive terms, this amounts to the claim that the subjective magnitude of a given item will be determined not just by the magnitude of that item but by the relation of that item's magnitude to the magnitudes of all the other items in the set to be judged. More specifically, subjective magnitudes will increase relatively quickly as a function of actual stimulus magnitude when stimuli are relatively similar to one another; subjective magnitude will increase more slowly with increasing actual magnitude in less crowded regions of stimulus space.

It seems plausible that such effects may be relevant to the understanding of temporal bisection. If it is assumed that the decision whether to respond "long" or "short" to a given duration is determined at least partly by the subjective magnitude of that duration, RFT would be expected to apply to performance on temporal bisection tasks. This is the hypothesis of TRFT. Further- more, as we now show, TRFT predicts shifts in the bisection point as a function of long:short ratio and stimulus spacing of exactly the type observed in the empirical literature. TRFT also makes novel predictions that we test below.

Why does TRFT predict that the bisection point should shift toward the lower end of a stimulus distribution as that distribution becomes more positively skewed? Consider the two illustrative distributions of durations in Figure 3. In both distribution $A$ (positively skewed) and distribution $B$ (negatively skewed), the shortest duration is $200 \mathrm{~ms}$, the longest is $800 \mathrm{~ms}$, and the midrange item (labeled $X$ ) is $500 \mathrm{~ms}$. According to the principles of TRFT, the subjective magnitude of $X$ will be higher in the positively skewed distribution than in the negatively skewed distribution (in intuitive terms, TRFT is taking account of the fact that $X$ is the eighth shortest out of the 10 durations in distribution $A$, whereas in distribution $B$ it is the third shortest duration). Stimulus $X$ will therefore be perceived as more similar to the long standard in the positively skewed distribution than it will be in the negatively skewed distribution. This will have the effect of shifting the bisection point to the left. Note that this corresponds exactly to what is often observed in the temporal bisection literature. The AM bisection (where the bisection point is shifted to the right compared with GM bisection) is more likely to be found when arithmetically spaced stimuli are used than when logarithmically spaced stimuli are used. Arithmetically spaced stimuli are negatively skewed compared with logarithmically spaced stimuli (analogously to distributions $B$ and $A$ in Figure 3, respectively), and so the empirically observed pattern is consistent with the predictions of TRFT.

We can illustrate the predictions of TRFT more concretely for sets of durations varying in both long:short ratio and in distribution (these are the durations that we use experimentally). Figure 4 illustrates eight different stimulus distributions. The top four distributions have a small long:short ratio (long $=666 \mathrm{~ms}$; short $=$ $333 \mathrm{~ms}$ ), while the lower four distributions have a large long:short ratio (long $=900 \mathrm{~ms}$; short $=100 \mathrm{~ms}$ ). For each ratio there are four different distributions varying in degree of positive skew. The topmost distribution contains negatively skewed stimuli, the second illustrates arithmetically spaced stimuli, the third illustrates logarithmically spaced stimuli, and the fourth illustrates more positively skewed stimuli. We refer to the first distribution as antilogarithmic spacing because the distribution is as negatively skewed relative to arithmetic spacing as a logarithmic distribution is positively skewed. The most positively skewed distribution is dubbed superlogarithmic distribution because it is as positively

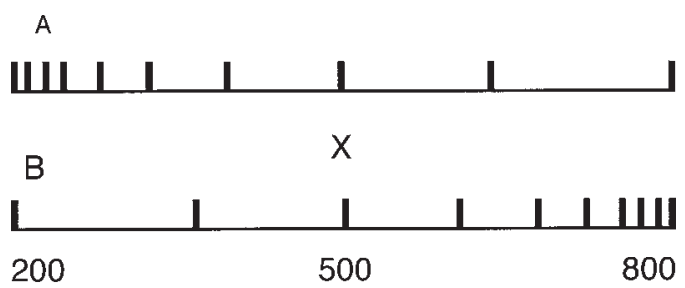

Tone Duration (ms)

Figure 3. Positively skewed (A) and negatively skewed (B) distributions of temporal durations. $\mathrm{X}=\mathrm{a}$ common point. 
$\circ \circ 000000$ Antilogarithmic

$\circ \quad \circ \quad \circ \quad \circ \quad \circ \quad \circ \quad \circ \quad \circ$ Arithmetic

00000000 Logarithmic

00000000 Superlogarithmic

\begin{tabular}{|c|c|c|c|c|c|c|c|c|c|}
\hline & 0 & & 0 & & 0 & & 0 & 0 & 00 \\
\hline & 0 & $\circ$ & 0 & o & & 0 & 0 & 0 & 0 \\
\hline & 00 & ० & ० & & $\circ$ & & $\circ$ & & 0 \\
\hline & $\infty 000$ & 0 & 0 & 0 & & & & & 0 \\
\hline 0 & 100 & 200 & 300 & 400 & 500 & 600 & 700 & 800 & 900 \\
\hline
\end{tabular}

Figure 4. The eight distributions of temporal durations used in Experiment 1 .

skewed relative to a logarithmic distribution as an arithmetic distribution is negatively skewed.

We applied TRFT to the illustrated distributions, after logarithmically transforming each stimulus value, and assumed a value of .5 for the weighting parameter $w$ (as is typically observed empirically). The resulting predicted subjective durations of each stimulus are illustrated for each of the eight distributions in the lefthand column of Figure 5. It can be seen that there are large predicted effects of stimulus distribution on subjective duration, and that these effects are substantially greater for the distributions where the long:short ratio is large. We also derived the predictions of a simple model of temporal bisection (developed in more detail below) according to which the probability of responding "long" to a given item is given by the similarity of the item's subjective magnitude to the subjective magnitude of the long standard relative to the summed similarity of the subjective magnitude of the stimulus to the subjective magnitudes of the short and long standards (i.e., we applied the Luce choice rule). Similarity was assumed to be a negative exponential function of the distance between items' subjective magnitudes. The results can be seen in the right-hand column of Figure 5. The predictions of this TRFTbased model are clear and striking. It can be seen that there is a leftward shift in the bisection point as the stimulus distribution becomes more positively skewed, and that this effect is much greater when the long:short ratio is large. Although the exact form of the curves, and in particular their steepness, depends upon the particular form and parameterization of the similarity function chosen, the qualitative effects do not.

Thus, TRFT offers a potential explanation of many of the observed effects of stimulus distribution and long:short ratio on the bisection point obtained in temporal bisection tasks. Furthermore, a clear novel prediction is made: It should be possible to shift the bisection point even further to the left or even further to the right than the GM and AM respectively if sufficiently skewed distributions are chosen. We test these predictions directly in the following experiments.

\section{Experiment 1}

The aim of Experiment 1 was to test two hypotheses. The first was that the distribution of durations within a stimulus set, and the ratio of the longest to the shortest duration in the set, will influence the bisection point in a temporal bisection task in ways consistent with the predictions of TRFT. This hypothesis was tested by examining the bisection point for sets of temporal durations that varied systematically in distribution and in long:short ratio. To the extent that the predictions of TRFT for shifts in temporal bisection point are confirmed, the need to postulate duration-specific accounts of shifts in temporal bisection point will be undermined.

The second hypothesis to be tested in Experiment 1 was that identification of durations makes use of the same basic processing mechanisms and decision processes as are used in identification of simple perceptual stimuli varying along other single dimensions (such as weight, line length, or frequency). This hypothesis was tested by examining absolute identification of durations in order to allow investigation of (a) serial position effects in absolute identification, (b) assimilation of responses to immediately preceding trials in absolute identification, and (c) contrast of responses to trials further back in the sequence. If a qualitatively similar pattern of sequential and serial position effects is obtained (as previously found with other dimensions), the results will go against claims that explanation of identification of temporal durations requires separate models such as those that have recently been developed in the literature.

In both parts of the experiment (absolute identification and temporal bisection) the same eight sets of stimuli were used (see Figure 4). Two long:short ratios (9:1 and 2:1) were crossed with four stimulus distributions (ranging from positively skewed to negatively skewed) in order to permit simultaneous assessment of ratio effects and distribution effects.

\section{Method}

Participants. Eighty volunteers from the University of Warwick participated in return for either course credit or a small fee. Ten participants were allocated to each of eight experimental conditions. Task order (absolute identification vs. temporal bisection) was manipulated within-subjects; 40 participants received the absolute identification task first, whereas 40 participants received the temporal bisection task first.

Materials. Eight sets of pure tones varying in duration were constructed to meet the requirements described above. Amplitude was constant throughout. The durations of the tones are given in Table 1, and the distributions are illustrated in Figure 4. Each tone was a constant $261.6 \mathrm{~Hz}$

Procedure. Tones were presented at a comfortable volume through Sennheiser eH2270 headphones via a Macintosh computer. Responses were recorded via keypresses on a labeled keyboard. For the absolute identification task keys in a horizontal row were labeled 1 through 8 ; for the bisection task one response key was labeled short and the other was labeled long.

The procedure for the absolute identification task was as follows. Participants were told that they would hear some tones and would have to identify them based on their duration. They were told that there was a set of eight tones that formed a series from short to long, with Tone 1 being the shortest in the series and Tone 8 being the longest, and that their task was to judge the number of each test tone that was presented. They were instructed to give a response to every trial even if they were unsure.

Each trial began with a 500-ms pause. A ? prompt was then displayed in the center of the screen, at the same time as the tone began. The prompt remained until the participant responded. The keys $F, G, H, J, V, B, N$, and $M$ were labeled $1,2,3,4,5,6,7$, and 8 . After the participant had 

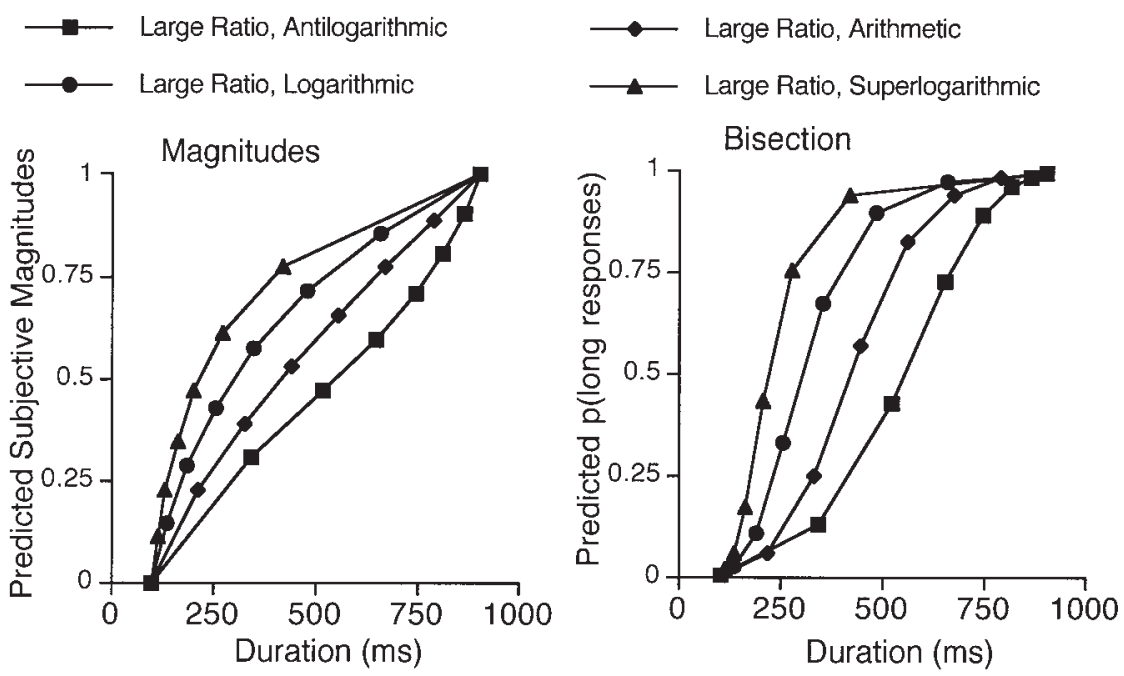
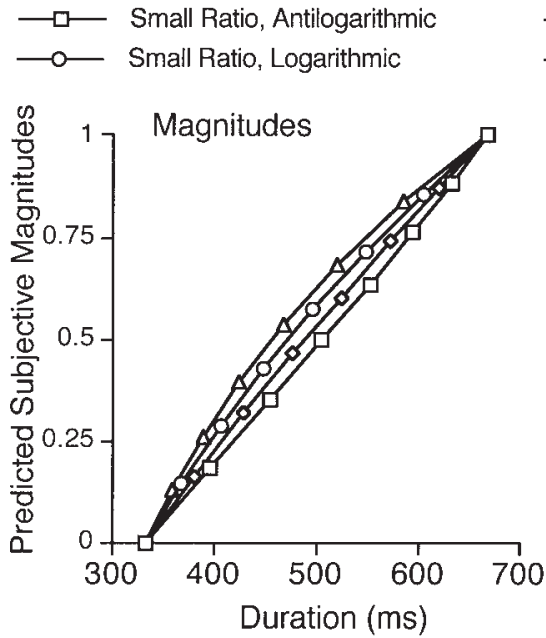
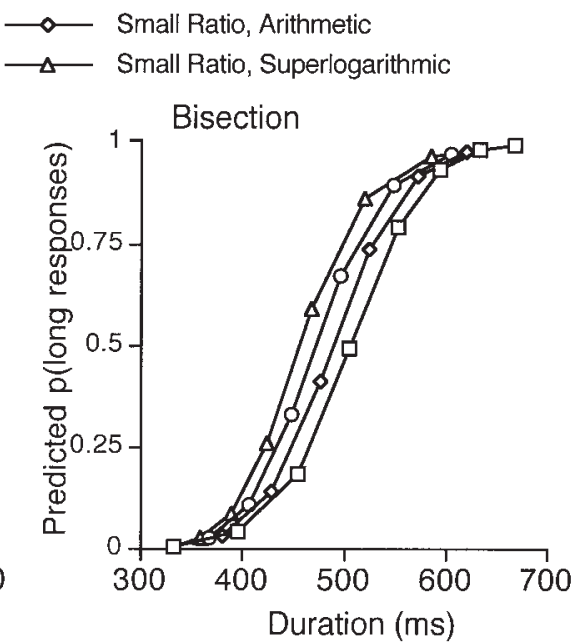

Figure 5. Predicted subjective magnitudes of temporal durations (left column) and predicted temporal bisection curves (right column) for stimulus distributions with large long:short ratios (top row) or small long:short ratios (bottom row).

responded, and not less than 2,000 ms from the stimulus onset, the correct number appeared in the center of the screen for $1,000 \mathrm{~ms}$. The screen was then blanked before the next trial. There were four blocks of 64 trials. Within the experiment each tone appeared 32 times. A tone (randomly selected without replacement from the $32 \times 8$ in the distribution condition to which the participant had been assigned) was presented on each trial.

The procedure for the temporal bisection task was as follows. Participants were told that they would hear some tones and would have to make judgments about them based on their duration. Specifically, participants were informed that they must decide whether each tone they heard was more similar to a "long" standard or a "short" standard and respond appropriately. They were instructed to give a response to every trial even if they were unsure.

In the initial exposure phase of the experiment, participants heard the shortest and then the longest standard four times. There was a 2,000-ms gap between tone onsets. This initial phase was followed by the main part of the experiment, which consisted of four blocks of 64 trials. Each tone appeared 32 times in the experiment. Every trial began with a 500-ms pause. A ? prompt was then displayed in the center of the screen, at the same time as the tone began. The prompt remained until the participant responded. The keys $Z$ and $X$ were labeled short and long, respectively. After the participant had responded, and not less than 2,000 ms from the stimulus onset, the next trial began. There was no feedback. On each trial, a randomly selected tone from the $32 \times 8$ in the distribution condition to which the participant had been assigned was presented.

\section{Results of Absolute Identification Task}

As several of the analyses involved investigation of sequence effects, we do not report results from the first 10 trials of each block because meaningful sequence effects may not be evident for these stimuli. For each condition overall level of correct performance (with no correction for response bias) is shown in Table 2. Figures 6,7 , and 8 summarize the results of the absolute identification conditions. Figure 6 shows the serial position curves; these were corrected for response bias by dividing the proportion of correct responses for a given item by the proportion of times that 
Table 1

Temporal Durations Used in Experiment 1 (in Milliseconds)

\begin{tabular}{cccc}
\hline Antilogarithmic & Arithmetic & Logarithmic & Superlogarithmic \\
\hline \multicolumn{4}{c}{ Large ratio } \\
100 & 100 & 100 & \\
343 & 214 & 137 & 100 \\
520 & 329 & 187 & 114 \\
649 & 443 & 256 & 134 \\
744 & 557 & 351 & 162 \\
813 & 672 & 480 & 203 \\
863 & 786 & 658 & 274 \\
900 & 900 & 900 & 420 \\
& & Small ratio & 900 \\
\hline & & 333 & 333 \\
333 & 333 & 368 & 359 \\
396 & 381 & 406 & 389 \\
453 & 428 & 448 & 424 \\
505 & 476 & 495 & 466 \\
551 & 524 & 547 & 518 \\
594 & 571 & 604 & 663 \\
632 & 619 & 666 & \\
666 & 666 & &
\end{tabular}

response was produced. ${ }^{1}$ Figure 7 shows the error on each trial as a function of the item presented on the immediately preceding trial, and Figure 8 shows the effect of both the immediately preceding and earlier trials.

We begin with the data in Figure 6, in which the general pattern of results can be summarized as follows. Overall level of performance was greater for more widely spaced stimuli (large long: short ratio). Clear serial position effects were obtained in all conditions, with an advantage for end-series stimuli. Superimposed on the serial position curves was a tendency for less accurate identification of durations more closely spaced within a range. These effects are very similar to those obtained in absolute identification of stimuli varying along nontemporal dimensions (Brown, Neath, \& Chater, 2002), and therefore appear consistent with the suggestion that similar psychological mechanisms may underpin identification of temporal and nontemporal stimuli (see the General Discussion below). The observations were confirmed by analysis. Analysis of correct responses revealed a main effect of ratio, $F(1,64)=92.09, M S E=1.86, p<.0001$, and a main effect of serial position, $F(7,448)=298.30, M S E=1.95, p<.0001$, but no main effect of distribution, $F(3,64)=0.83, M S E=0.02, p=$ .48. There was an interaction between ratio and serial position, $F(7,448)=6.37, M S E=0.04, p<.0001 ;$ an interaction between distribution and serial position, $F(21,448)=41.80, M S E=0.27$,

Table 2

Proportion of Correct Absolute Identification Performance in Experiments 1 and 2

\begin{tabular}{lccccc}
\hline \multirow{2}{*}{\multicolumn{1}{c}{ Measure }} & \multicolumn{2}{c}{ Experiment 1} & & \multicolumn{2}{c}{ Experiment 2} \\
\cline { 2 - 3 } \cline { 5 - 6 } \cline { 5 - 6 } Aarge ratio & Small ratio & & Large ratio & Small ratio \\
\hline Arithmetic & .416 & .298 & & .565 & .530 \\
Logarithmic & .431 & .311 & & .644 & .635 \\
Superlogarithmic & .401 & .292 & & .631 & .561 \\
\hline
\end{tabular}
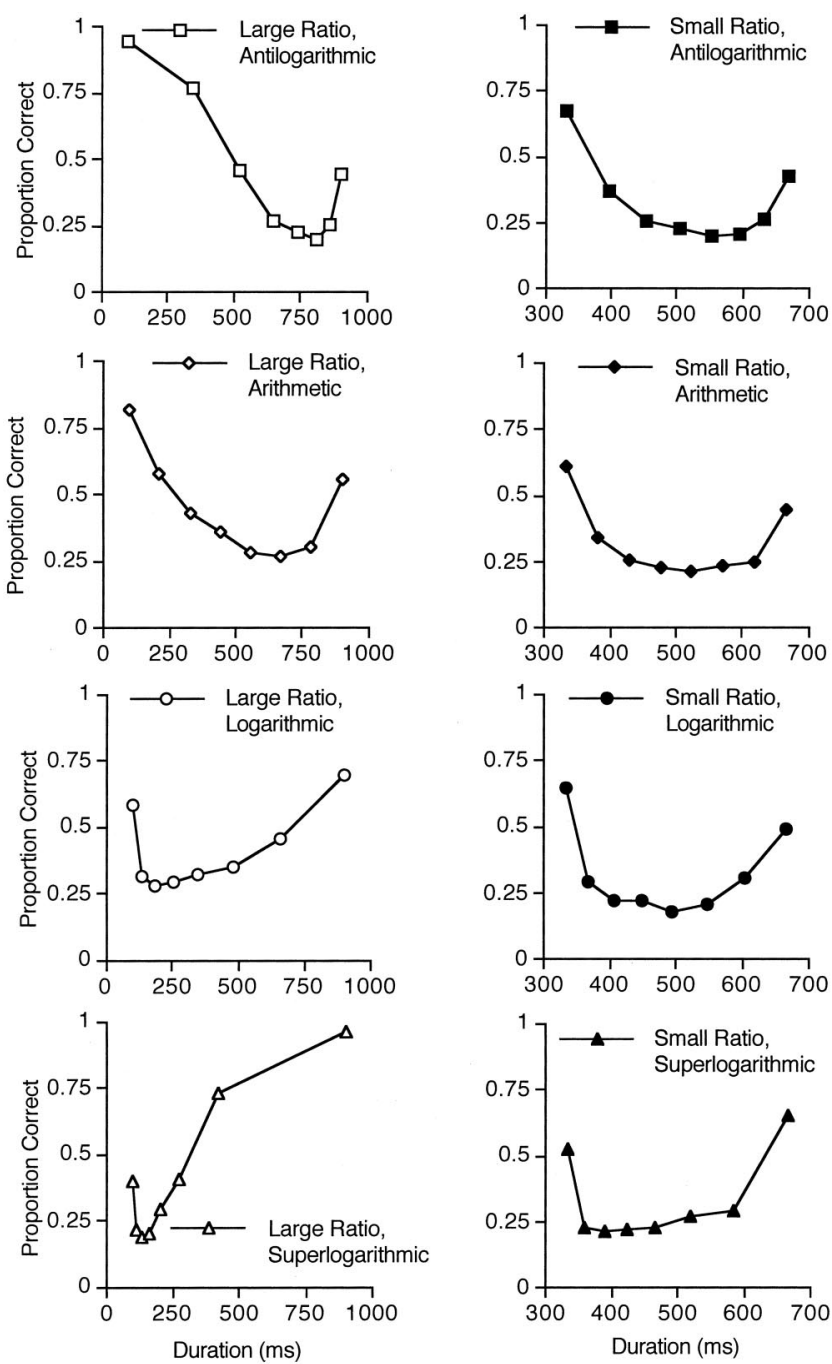

Figure 6. Serial position curves obtained from absolute identification of stimulus durations (Experiment 1).

$p<.0001$; and a three-way interaction between ratio, distribution, and serial position, $F(21,448)=16.90, M S E=0.11, p<.0001$.

The order variable (whether the absolute identification task or the bisection task was carried out first) did not give rise to a significant main effect or any two-way interactions, but there was a three-way interaction between order, ratio, and condition, $F(3,64)=3.67$, $M S E=0.08, p=.016$. This interaction was small in magnitude, and we do not discuss it further.

The next set of analyses examined sequence effects in the same way as is typically done in the analysis of identification of nontemporal stimuli. It is typically found that errors are systematic. For example, if Stimulus 1 (the shortest duration) is presented on trial $n-1$, and Stimulus 8 (the longest duration) is presented on trial $n$, the mean error is normally negative; a mean error of -1.5

\footnotetext{
${ }^{1}$ This correction procedure can lead to distortion of the data when response bias is large and systematic, but is unproblematic when, as here, participants exhibit small and nonsystematic preferences for particular responses.
} 


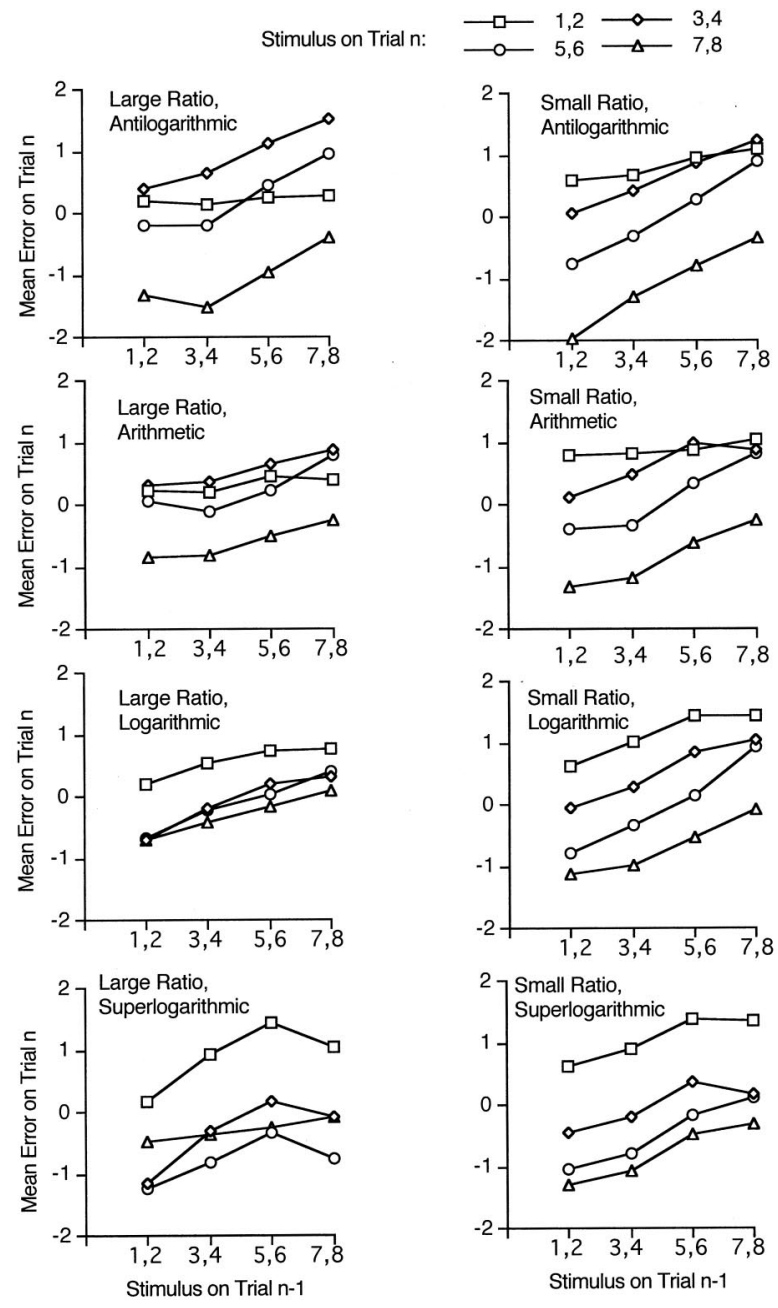

Figure 7. Effects of stimulus in trial $n-1$ on mean error in trial $n$ for absolute identification of temporal durations (Experiment 1).

would indicate that the mean response to Stimulus 8 is 6.5 (i.e., assimilation is observed). We therefore examined the mean error on trial $n$ as a function of stimulus on trial $n$ and stimulus on trial $n-1$ (see Figure 7). Each panel shows these data for a given combination of ratio and distribution and may be interpreted as follows. Each line represents the mean errors for pairs of adjacent stimuli. To the extent that the lines in a given panel have a nonzero slope, there is an effect of trial $n-1$ on response $n$. To the extent that the lines are separated, are positive in slope, and cross zero, there is assimilation to the previous trial.

Analyses of variance (ANOVAs) revealed a main effect of stimulus on trial $n, F(3,192)=401.66, M S E=123.20, p<.001$; and of stimulus on trial $n-1, F(3,192)=175.38, M S E=50.89$, $p<.0001$; with a significant interaction between them, $F(9$, $576)=13.33, M S E=1.52, p<.0001$. These effects reflect a tendency for responses on a given trial to be assimilated toward (i.e., correlated with) the stimulus on trial $n-1$, with this effect being greater as the difference between the stimuli on trial $n$ and on trial $n-1$ increases. There are therefore clear sequential effects apparent in identification of temporal duration, and these exhibit the same pattern as is typically observed for nontemporal dimen- sional stimuli. The main effects of trial $n$ and of trial $n-1$ interacted in various ways with ratio and with distribution, and various higher-order interactions were evident. We do not report these interactions in detail, however, as our main purpose is to show that the normal effects of assimilation are evident, and as analysis of simple main effects revealed effects of both trial $n$ and of trial $n-1$ for each ratio and for each distribution: for the effects of stimulus on trial $n$, all $F \mathrm{~s}(3,192)>80, M S E=0.31$; for the effects of stimulus on trial $n-1$, all $F \mathrm{~s}(3,192)>25, M S E=0.29$, $p<.0001$ in all cases.

The final analyses of sequence effects examined mean error on trial $n$ (averaged over different stimuli on trial $n$ ) as a function of the stimulus on trial $n-k$ and of $k$. Data are shown in Figure 8. Overall, as is observed with identification of nontemporal stimuli, there is a clear tendency for assimilation of the response to the stimulus on trial $n-1$, and a weaker tendency for contrast between responses on trial $n$ and stimuli on trials $n-k(k \geq 2)$ The statistical significance of assimilation and contrast effects was assessed through regression analyses, carried out for individual participants, to assess the correlations between response on trial $n$
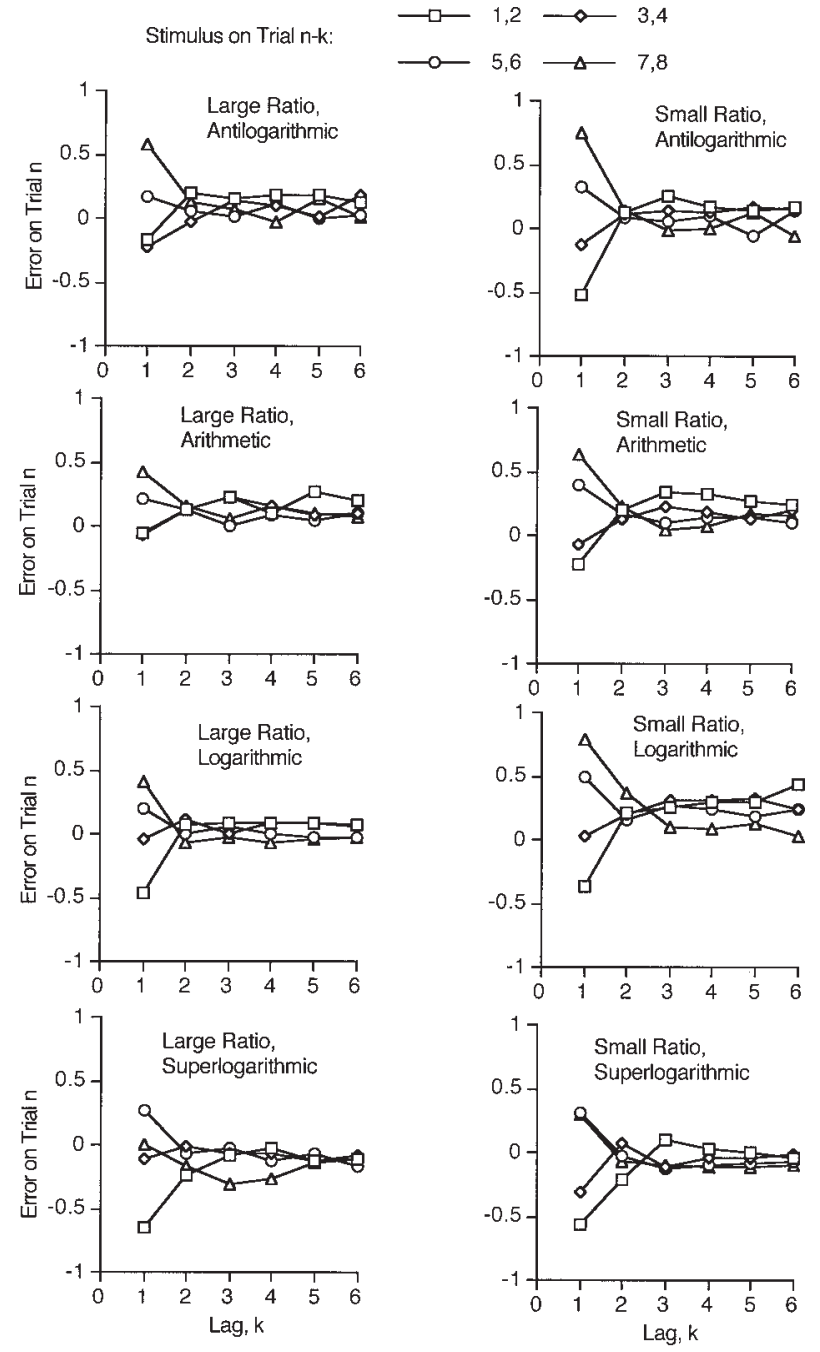

Figure 8. Contrast and assimilation effects observed in the absolute identification of temporal duration (Experiment 1). 
and the stimulus on trial $n-k$ (where $k$ took values 1 through 5). Note that the sequences were virtually random; there was effectively no correlation between the stimulus on trial $n$ and on trial $n-k$. Figure 9 shows the mean regression coefficients for lags 1 through 5. A positive coefficient reflects assimilation (i.e., a positive correlation between response $n$ and stimulus $n-k$ ); a negative coefficient reflects contrast. All coefficients except for lag $=2$ were significantly different from zero, all $t \mathrm{~s}(79)>3.3$, $p<.001$ in all cases. Thus the classic pattern of assimilation to immediately preceding stimuli, and contrast to more distant stimuli, was evident. ANOVAs on the coefficient values revealed no effect of ratio or distribution on the coefficient values at any lag $(p>.05$ in all cases).

\section{Discussion of Absolute Identification Results}

The aim of the absolute identification analyses was to determine whether absolute identification of temporal durations would show similar effects to absolute identification of stimuli varying unidimensionally along nontemporal dimensions. The results were consistent with the suggestion that similar mechanisms are involved in identification of temporal durations as researchers have previously investigated for other dimensions. First, clear serial position effects were observed. These have previously been observed for absolute identification of line length (Bower, 1971), area (Eriksen \& Hake, 1957), position along a semantic continuum (DeSoto \& Bosley, 1962; Pollio \& Deitchman, 1964, cited in Bower, 1971), spatial position (Ebenholtz, 1963; Jensen, 1962), brightness (Bower, 1971), temporal duration (Lacouture et al., 2001), and tone frequency (Brown et al., 2002; Experiment 2 of this paper). Moreover, the serial position effects were asymmetrical, reflecting lower levels of performance in relatively crowded regions of stimulus space. Similar effects have been found for tone frequency (Brown et al., 2002); we investigate parallels in detail in Experiment 2 .

Second, there was clear evidence of assimilation of responses to immediately preceding trials. Such effects have previously been observed in judgments of other dimensions (e.g., Garner, 1953; Holland \& Lockhead, 1968; Hu, 1997; Lacouture, 1997; Lock-

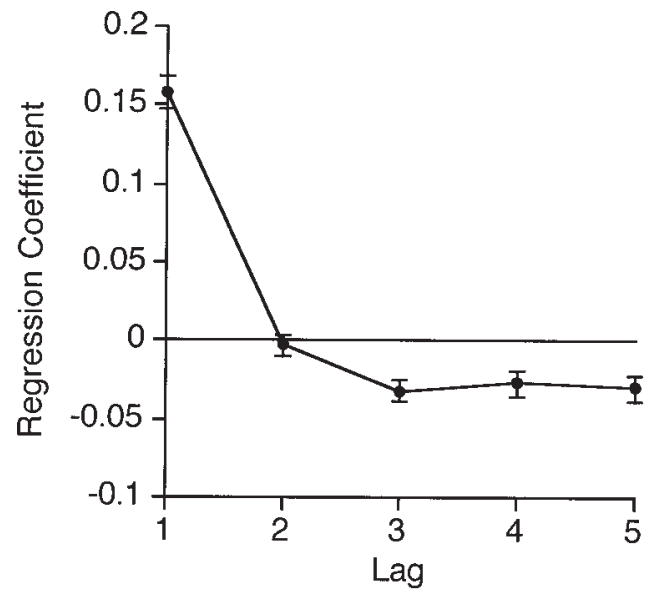

Figure 9. Regression coefficients observed in analysis of sequence effects in identification of temporal durations (Experiment 1). Error bars represent standard errors. head, 1984; Long, 1937; Luce et al., 1982; Purks, Callahan, Braida, \& Durlach, 1980; Staddon, King, \& Lockhead, 1980; Ward \& Lockhead, 1970, 1971). Third, there was evidence of contrast of responses to trials further back in the sequence; this result again parallels findings in absolute identification of other dimensions (e.g., Holland \& Lockhead, 1968; Lacouture, 1997; Ward \& Lockhead, 1970, 1971).

Overall, then, the key effects observed in identification of nontemporal dimensions are also obtained in duration identification, consistent with the general claim that similar models may be applicable in both cases.

\section{Results of Temporal Bisection Task}

Analysis of the temporal bisection data focused on two key questions. The first question was whether the bisection point would shift as a function of the distribution of durations within a set and with the long:short ratio. Such shifts are predicted by TRFT (cf. Figure 5) and have already been observed when only arithmetic and logarithmic stimulus spacings are used (Allan, 2002b; Penney et al., 1998; Wearden \& Ferrara, 1995, 1996; Wearden et al., 1997). The second more general question was whether a model of bisection based on TRFT principles would permit a good fit to the observed data.

The overall results are shown in Figure 10. It is evident that the overall pattern of results corresponds qualitatively to the predictions, with a wider separation of the bisection curves for the large-ratio conditions and the predicted shift in bisection points. In order to provide a more detailed assessment, we first estimated a bisection point for each individual participant. This was done by fitting the equation

$$
p\left(\operatorname{long} \mid D_{i}\right)=\frac{1}{1+e^{-s\left(D_{i}-t\right)}}
$$

to each participant's data, where $D_{i}$ is duration $i$, and estimating for each participant the parameters $t$ (bisection point) and $s$ (steepness of the function). The equation did well at fitting individual participant data (median $R^{2}=.987$ ). The resulting mean estimated bisection points are shown in Figure 11a, where there is a clear tendency, as predicted, for the bisection point to become larger in the more positively skewed distributions in which the long:short ratio is large. This tendency appears much smaller when the long:short ratio is small, again as predicted by TRFT.

ANOVAs confirmed these impressions. There was a main effect of ratio, $F(1,64)=29.42, M S E=114,943.59, p<.0001$; a main effect of distribution, $F(3,64)=22.60, M S E=88,354.22, p<$ .0001 ; and an interaction between ratio and distribution, $F(3$, $64)=14.44, \operatorname{MSE}=56,452.43, p<.0001$.

Note that in the small ratio conditions the GM and the AM are $471 \mathrm{~ms}$ and $500 \mathrm{~ms}$, respectively, whereas in the large ratio condition the GM and AM are $300 \mathrm{~ms}$ and $500 \mathrm{~ms}$, respectively. Thus when the stimulus distribution is sufficiently extreme, and when the long:short ratio is large, the observed bisection point may either exceed the AM (antilogarithmic distribution) or fall below the GM (superlogarithmic distribution). The observed bisection points for the arithmetic and logarithmic distributions are generally consistent with previous results, being closer to the GM and AM for logarithmically and arithmetically spaced stimuli respectively. We next examined the ability of a TRFT-based model of bisection to account for the complete bisection curves. 

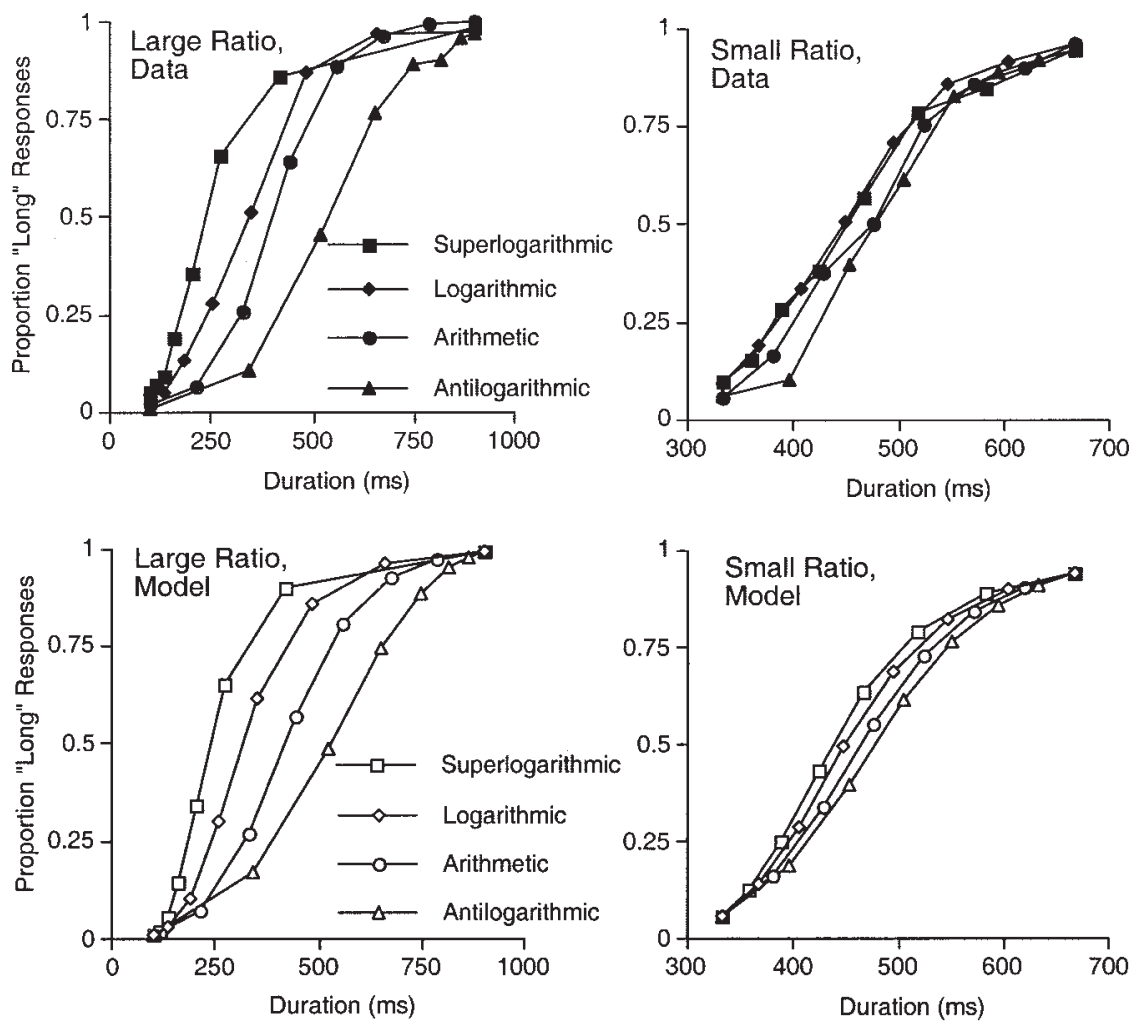

Figure 10. Observed temporal bisection curves (top row) and fit of the model to the data (bottom row).

\section{Modeling}

The aim of the modeling was to determine whether the basic qualitative patterns observed in the temporal bisection data (particularly the shifts in bisection point resulting from changes in stimulus spacing and long:short ratio) could be captured in a simple model that incorporated the basic principles of TRFT. In order to preserve transparency of explanation we therefore aimed to produce a simple model with relatively few parameters rather than a more detailed and perhaps overparameterized model that might produce a better fit to the data but at the cost of obscuring the relation between model and data.

The model we explored was essentially an exemplar model of identification, similar to those proposed in other (nontemporal) domains. The model makes two core assumptions. First, it is assumed that the subjective magnitude of a given duration is determined according to the principles embodied in TRFT. Second, when the subjective magnitude of a test duration has been calculated, the probability of responding "long" to that duration is given by the psychological similarity of the test duration to the long standard divided by its summed similarity to the long and the short standard. (This latter assumption is essentially a simple application of the Luce choice model.) Many extant models of temporal bisection assume that each test stimulus is compared to the long and/or short standard; our aim in the modeling was to incorporate TRFT while making as few additional assumptions as possible.

These assumptions were implemented as follows. First, the subjective magnitude $M_{i}$ of a test duration, $S_{i}$, is calculated according to Equation 1 above, with prior logarithmic transformation of the stimulus durations (discussed below). Second, the probability of responding "long" given a test duration of psychological magnitude $M_{i}$ is given by

$$
P\left(\operatorname{Long} \mid M_{i}\right)=\frac{\eta_{i, L}}{\eta_{i, L}+\eta_{i, S}},
$$

where $\eta_{i, j}$ is the psychological similarity between $M_{i}$ and $M_{j} ; M_{\mathrm{L}}$ is the psychological magnitude of the long duration and $M_{\mathrm{S}}$ is the psychological magnitude of the short duration, and the similarity of $M_{i}$ and $M_{j}$ is given by

$$
\eta_{i, j}=e^{-c\left|M_{i}-M_{j}\right|^{a}}
$$

This similarity-distance model, which is widely used in models of generalization, categorization, and memory (e.g., Nosofsky, 1986; Shepard, 1987b), has the effect of reducing the psychological similarity between any two magnitudes as a function of the psychological distance between them. The scaling parameter $c$ governs the rate at which similarity and confusability decrease with distance; in previous work on absolute identification, we have found that larger values of $c$ must be associated with larger ratios between the smallest and largest magnitudes within a stimulus set to account for small or absent effects of stimulus range (Brown et al., 2002). The same was true in this experiment (to anticipate the model-fitting procedure described below). Finally, the $a$ parameter describes the form of the generalization gradient. When $a=2$, the similarity-distance function is Gaussian in form. Gaussian similarity-distance functions may provide the best characterization of human identification data when the stimuli are sufficiently close 
a

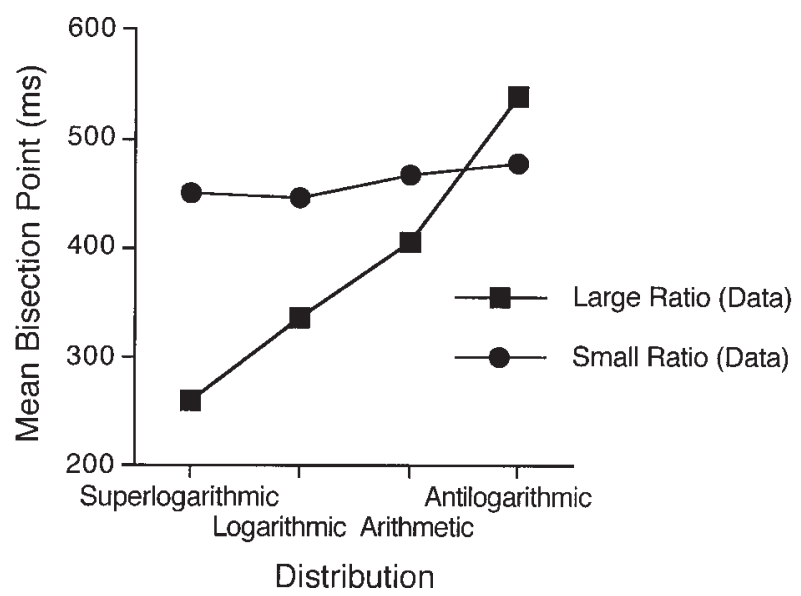

b

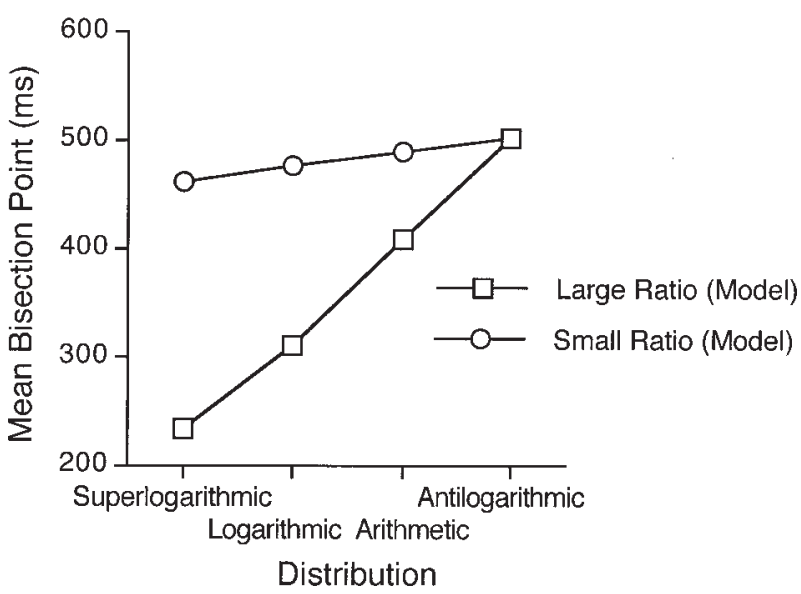

Figure 11. Observed (a) and predicted (b) temporal bisection points as a function of stimulus distribution and long:short ratio.

in psychological space that perceptual confusability of stimuli or noise in perceptual representations may be a significant factor in performance (Ennis, 1988; Nosofsky, 1988; Shepard, 1987a). When $a=1$, the similarity-distance function is exponential in form, and when (as here) magnitudes are assumed to be represented on a logarithmic internal scale, this has the consequence that the psychological similarity between any two temporal durations would simply be a function of the ratio of the shorter to the longer if TRFT principles were not applied. More specifically, when $w=1, c=1$, and $a=1$, the model reduces to a simple ratio-based similarity model akin to many previous models of temporal bisection. Thus the use of a logarithmic transformation of stimulus durations should not be taken as a strong claim that the psychological magnitudes of temporal durations are logarithmic; instead the formalism allows extension of a ratio-based similarity metric in a straightforward manner. For simplicity and transparency of interpretation, we held $a$ constant at 1.0 in all simulations below; additional unreported simulations found that allowing $a$ to vary led to only small improvements in fit (adding less than $0.5 \%$ to the variance accounted for) and did not change the qualitative behavior of the model in any way.

There are thus two free parameters. The $w$ parameter, which specifies the relative weight given to the ordinal position of a test duration in a series in determining its psychological magnitude, was held constant for all spacing and both long:short ratios. The $c$ parameter was allowed to vary with ratio but not with distribution; this decision was motivated by the a priori theoretical expectation that $c$ would be higher when the long:short ratio is larger.

Best-fitting parameter values were obtained, and the resulting model behavior is shown in Figure 10 (lower two panels). The parameter values that gave rise to the observed output were $w=$ .49 (all conditions), $c=4.5$ (large ratio), and $c=2.8$ (small ratio). The overall $R^{2}$ obtained was .98 .

The bisection points derived from the model's data are shown in Figure 11b. It is evident that the model does well at capturing the key changes in bisection points as a function of changes in ratio and distribution, despite the fact that the parameter fitting procedure did not optimize fits for these points directly.

The best-fit parameter values were generally in accordance with expectations. The value of .49 for the weighting parameter (which determines the relative importance of ordinal position and location with respect to endpoints in the calculation of subjective magnitude) is close to that obtained in other studies involving magnitude estimation for other dimensions (e.g., Parducci, 1995). It was predicted on the basis of previous work with nontemporal stimuli (Brown et al., 2002) that the $c$ parameter would be larger when the long:short ratio was large, and this proved to be the case.

Most important, the model captures the tendency of bisection points to change as a function of stimulus spacing, and for change to be larger when the ratio between the longest and the shortest duration is large. As we noted in the introduction, this is essentially the pattern that has often been obtained in the previous literature, although the empirical effects have not always been clear perhaps because the distributions used in previous experiments (linear and logarithmic) were not so extreme. Why does the model exhibit this behavior? The crucial feature of the model is the assumption that the principles embodied in TRFT are relevant to determining the subjective magnitude of a given temporal duration. Temporal range frequency theory offers a principled account, one developed independently on the basis of models of data from nontemporal domains, for the effects of distribution. Thus one feature of the current model that sharply distinguishes it from most models of timing is its assumption that durations are not perceived in isolation, or even simply in terms of their relation to the shortest and longest durations in an experimental set. Rather, the distribution of all durations within the experiment influences the treatment of any one of them, exactly as predicted by TRFT. Another feature of the current approach is its importation of the terminology and machinery of exemplar theory into models of timing (see also McCormack et al., 2002); potential advantages of this strategy include (a) the possibility of integrating models of timing more closely with models independently developed in other areas and (b) the ability to make use of the modeling machinery developed and well understood in the context of models of identification, categorization, and recognition.

In other respects the model proposed here is highly similar to previous models. In particular, we note that when $a, w$, and $c$ all $=1$, the similarity of any two durations (e.g., a test duration and the long or the short standard) is simply a function of their ratio. 


\section{Experiment 2}

Experiment 1 found that many of the classic effects previously obtained from studies of absolute identification of nontemporal stimuli were also obtained when stimuli varying in duration had to be identified. One aim of Experiment 2 was to confirm that the same effects emerge when stimuli varying in frequency must be identified when the experimental conditions correspond exactly to those used in Experiment 1.

The main aim of Experiment 2 was to examine whether the shifts in bisection point found in Experiment 1 for temporal stimuli could also be observed in an analogous frequency-bisection task. If similar effects are found when frequency rather than duration is the relevant stimulus dimension, further evidence will be consistent with the hypothesis that similar psychological mechanisms are involved in identification of both temporal and nontemporal stimuli.

In Experiment 2, therefore, we replicated the conditions of Experiment 1 as closely as possible, with the single difference that stimuli were tones varying in frequency rather than tones varying in duration.

\section{Method}

Participants. Eighty volunteers from the University of Warwick participated in return for either course credit or a small fee. Ten participants were allocated to each of eight experimental conditions. All participants completed both the absolute identification and bisection tasks. Forty participants received the absolute identification task first, whereas 40 participants received the bisection task first.

Materials. Eight sets of eight pure tones, constant in amplitude but varying in frequency, were constructed to have the same distributional properties as the durations used in Experiment 1. The frequencies of the tones are given in Table 3. Each tone lasted $500 \mathrm{~ms}$.

Procedure. Tones were presented through Sennheiser eH2270 headphones at a comfortable volume via a Macintosh computer. Responses were recorded via keypresses on a labeled keyboard. The procedure for the absolute identification task was identical to that used in Experiment 1, with the exception that the eight stimuli were tones varying in frequency and

Table 3

Frequencies Used in Experiment 2 (in Hertz)

\begin{tabular}{rrrr}
\hline \multirow{4}{*}{ Antilogarithmic } & Arithmetic & Logarithmic & Superlogarithmic \\
\hline \multicolumn{3}{c}{ Large ratio } \\
200 & 200 & 200 & 200 \\
685 & 429 & 274 & 229 \\
1,039 & 657 & 375 & 268 \\
1,298 & 886 & 513 & 323 \\
1,487 & 1,114 & 702 & 406 \\
1,625 & 1,343 & 961 & 548 \\
1,726 & 1,571 & 1,315 & 840 \\
1,800 & 1,800 & 1,800 & 1,800 \\
& & Small ratio & 666 \\
666 & 666 & 666 & 718 \\
792 & 762 & 736 & 878 \\
906 & 857 & 813 & 933 \\
1,009 & 952 & 897 & 1,037 \\
1,103 & 1,048 & 991 & 1,167 \\
1,187 & 1,143 & 1,094 & 1,333 \\
1,264 & 1,238 & 1,208 & \\
1,333 & 1,333 & 1,333 & \\
\hline
\end{tabular}

forming a series from low to high, with Tone 1 being the lowest in the series and Tone 8 the highest. Instructions to participants were modified to reflect this change. The frequency bisection task was again identical to that used in Experiment 1, except that the long and the short tones were replaced with high and low tones, and the instructions to participants were modified accordingly.

\section{Results of Absolute Identification Task}

An important component of the analyses involved investigation of sequence effects; we do not report results from the first 10 trials of each block because meaningful sequence effects may not be evident for these stimuli. Figures 12, 13, and 14 summarize the results of the absolute identification conditions in a format similar to the one that was used for durations, although we report results in less detail as our aim is simply to confirm previous findings. Figure 12 shows the serial position curves (corrected for response bias), Figure 13 shows the error on each trial as a function of the item presented on the immediately preceding trial, and Figure 14 shows the effect of both the immediately preceding and earlier trials. In Figures 13 and 14, data are collapsed over distribution and high:low ratio.

We begin with the data in Figure 12 (level of correct performance as a function of condition and serial position). The overall pattern was essentially identical to that observed for durations, but performance was somewhat higher overall. Overall level of performance was greater for more widely spaced stimuli (large long: short ratio); clear serial position effects were obtained in all conditions, with an advantage for end-series stimuli, and there was a tendency for less accurate identification of stimuli more closely spaced within a range.

For each condition, overall level of correct performance (with no correction for response bias) is shown in Table 2. Analysis of correct responses revealed a marginally significant effect of ratio, $F(1,64)=3.38, M S E=0.31, p=.071$; a main effect of serial position, $F(7,448)=202.88, M S E=1.87, p<.0001$; but no main effect of distribution, $F(3,64)=2.10, M S E=0.19, p=.11$. There was an interaction between ratio and serial position, $F(7,448)=$ 2.35, $M S E=0.02, p<.0229$; an interaction between distribution and serial position, $F(21,448)=13.94, M S E=0.13, p<.0001$; and a three-way interaction between ratio, distribution, and serial position, $F(21,448)=4.76, M S E=0.04, p<.0001$. The order variable did not give rise to a significant main effect or any interactions. This pattern of results is qualitatively the same as that obtained in Experiment 1, except that in the present experiment the effect of ratio was only marginally significant.

We now turn to analysis of sequential effects. The first set of analyses examined error on trial $n$ as a function of stimulus on trial $n$ and stimulus on trial $n-1$ (see Figure 13). The overall mean error on trial $n$ as a function of both the stimulus on trial $n$ and the stimulus on trial $n-1$ is shown. The data have been collapsed across distribution and ratio as the data otherwise appear somewhat noisy, and we are in any case concerned simply to show that the standard findings replicate; the lower panel of Figure 13 shows the equivalent plot for Experiment 1 data for ease of comparison. Note that the current effects are smaller in magnitude than were observed in Experiment 1; there is a change of scale on the figure. The interpretation of the figure is the same as previously: To the extent that the lines have a nonzero slope, there is an effect of trial $n-1$ on response $n$; and to the extent that the lines are separated, are positive in slope, and cross zero, there is assimilation to the previous trial. 

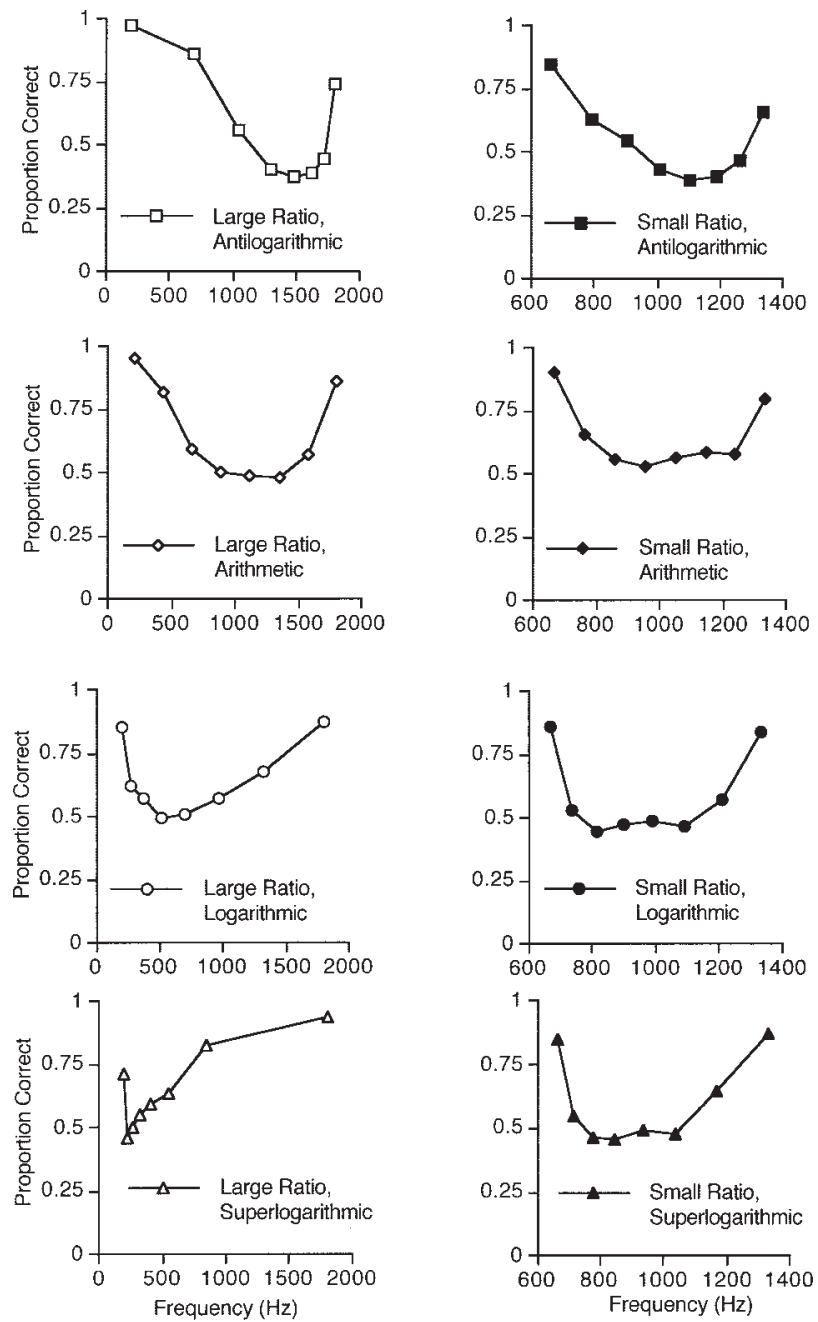

Figure 12. Serial position curves obtained from absolute identification of tone frequencies (Experiment 2).

ANOVAs revealed a main effect of stimulus on trial $n, F(3$, $192)=114.81, M S E=23.04, p<.0001 ;$ and of stimulus on trial $n-1, F(3,192)=55.41, M S E=7.31, p<.0001$, with a significant interaction between them, $F(9,576)=5.45, M S E=$ $0.48, p<.0001$. These effects reflect a tendency for responses on a given trial to be assimilated toward (i.e., correlated with) the stimulus on trial $n-1$, with this effect being greater as the difference between trial $n$ and trial $n-1$ increases. There are therefore clear sequential effects in identification of tones varying in frequency, replicating previous results with other stimuli, including the durations used in Experiment 1. The main effects of trial $n$ and of trial $n-1$ interacted in various ways with ratio and with distribution, and various higher-order interactions were evident. We do not report these interactions in detail, however, as our main purpose is to show that the normal effects of assimilation are evident, and as analysis of simple main effects revealed effects of both trial $n$ and of trial $n-1$ for each ratio and for each distribution: for the effects of stimulus on trial $n$, all $F_{\mathrm{S}}(3,192)>$ $10.57, M S E=0.20$; for the effects of stimulus on trial $n-1$, all $F_{\mathrm{S}}(3,192)>21.00, M S E=0.13, p<.001$ in all cases, except that there was no effect of trial $n-1$ for the logarithmically spaced condition, $F(3,192)=0.90, p=.445$.

Finally, as in the analyses of Experiment 1, we examined how the error on trial $n$ varies as a function of stimuli presented on previous trials (up to five backward in the sequence). Figure 14 shows the average error on trial $n$ (averaged over all possible trial $n$ stimuli) as a function of the stimuli presented on trial $n-k$ and $k$. As in Figure 13, the figure shows the data averaged over condition because the data otherwise appear somewhat noisy and the primary aim is to examine comparability with equivalent effects seen in duration identification in Experiment 1. The lower panel of Figure 14 shows the equivalent averaged data from Experiment 1. It is evident that a qualitatively similar (albeit less marked) pattern of assimilation and contrast is observed, with the response on trial $n$ being assimilated toward the stimulus presented on trial $n-1$ but being negatively correlated (i.e., contrasted with) stimuli presented on trial $n-k(k>1)$.

The statistical significance of assimilation and contrast effects was again assessed through regression analyses, carried out for individual participants. Figure 15 shows the mean regression coefficients for lags 1 to 5 . A positive coefficient reflects assimilation (i.e., a positive correlation between response $n$ and stimulus $n-$ $k$ ); a negative coefficient reflects contrast. All coefficients were significantly different from zero except for lag $=2$ : all $t \mathrm{~s}(79)>$ $2.8, p<.01$ in all cases. Thus the classic pattern of assimilation to immediately preceding stimuli, and contrast to more distant stimuli, was evident as for temporal durations (Figure 9 above) and
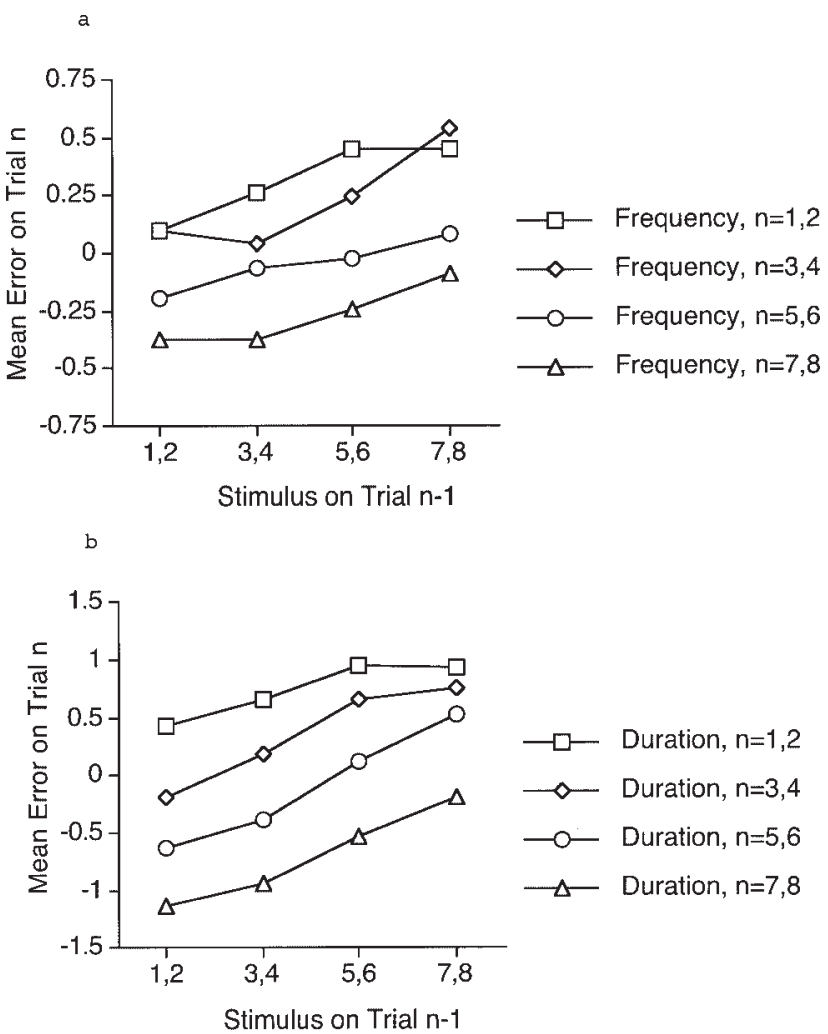

Figure 13. Summary of effects of stimulus in trial $n-1$ on mean error in trial $n$ for absolute identification of tone frequencies (Experiment 2; a) and stimulus durations (Experiment $1 ; b)$. Note that axes differ. 
a

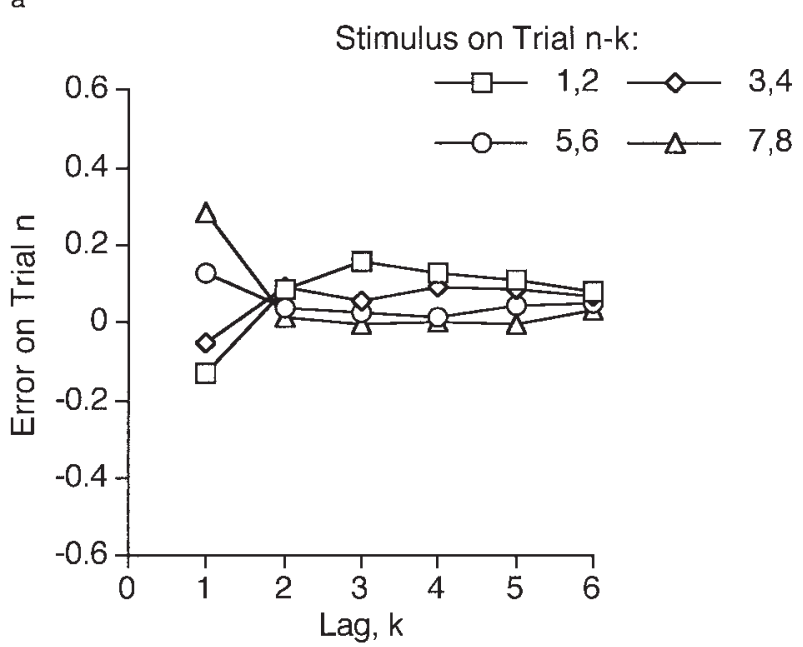

b

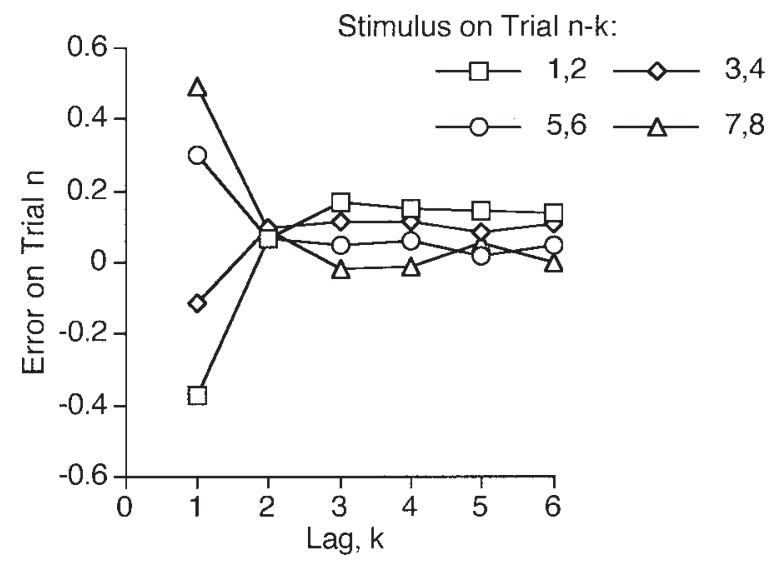

Figure 14. Contrast and assimilation effects observed in absolute identification of tone frequencies (Experiment 2; a) and stimulus durations (Experiment $1 ; \mathrm{b})$.

consistent with previous research on other dimensions. ANOVAs on the coefficient values revealed no effect of ratio or distribution on the coefficient values at any lag ( $p>.1$ in all cases).

Overall, the key effects parallel those observed in absolute identification of duration in Experiment 1. Serial position effects were similar, with an overall tendency for $U$-shaped serial position curves superimposed on a tendency for stimuli that were relatively closely spaced to be less accurately identified. Sequential effects, although smaller in Experiment 2 than in Experiment 1, followed the same pattern with both assimilation and contrast to previous stimuli.

\section{Results of Frequency Bisection Task}

The final analyses focused on the frequency bisection task. The key question of interest was whether shifts in the frequency bisection point as a function of stimulus distribution and the ratio of the extreme stimuli occur in the same way as observed for bisection of temporal duration in Experiment 1.

The results are shown in Figure 16. The top two panels show the frequency bisection data for the large ratio and small ratio condi- tions respectively; the lower two panels show the fit of the model as described below. We first report conventional statistical analyses. The first step was to estimate each individual participant's bisection point by fitting a sigmoid curve to each individual participant's data as was done for Experiment 1. The median $R^{2}$ value for this preliminary curve fitting was .981. The estimated bisection points are shown in Figure 17 (top panel) where it is evident that there was a clear tendency for the bisection point to be smaller for the more negatively skewed distributions. This parallels the effect seen in Experiment 1, and conforms to the predictions of the RFT-derived model described there. Also, as in Experiment 1 , the effect of stimulus spacing was much greater when the ratio of the two extreme stimuli (in this case the ratio of the highest to the lowest frequency) was greater.

ANOVAs confirmed these impressions. There was a main effect of ratio, $F(1,64)=41.29, M S E=435,600.65, p<.001$; a main effect of distribution, $F(3,64)=63.00, M S E=664,772.84, p<$ .001 ; and an interaction between ratio and distribution, $F(3,64)=$ 37.50, $M S E=395,696.65, p<.001$.

It is noteworthy that, as in Experiment 1, the frequency bisection point could, when the skew of the stimulus distribution was sufficiently extreme, either exceed the arithmetic mean of the highest and lowest stimuli, or fall below the geometric mean. We next examined the ability of the RFT-based model of bisection to account for the results.

\section{Modeling}

The purpose of the modeling was to assess the ability of the model of temporal bisection that we developed in the context of Experiment 1 to account for the new frequency bisection results. The fit of the model to the complete bisection curves is shown in the lower two panels of Figure 16 and the bisection points of the model are shown in the lower panel of Figure 17. It is evident that a reasonably good fit was obtained, and that all the key effects were captured by the model. As before, the weighting parameter $w$ was held constant for all conditions; it was estimated at .35 . The parameter $c$ was 4.7 (large ratio) and 3.9 (small ratio). The overall $R^{2}$ obtained was .99 .

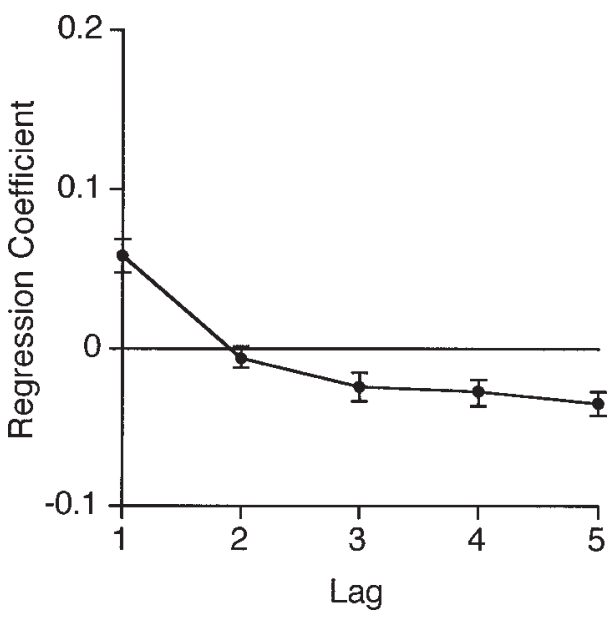

Figure 15. Regression coefficients observed in analysis of sequence effects in identification of tone frequencies (Experiment 2). Error bars represent standard errors. 

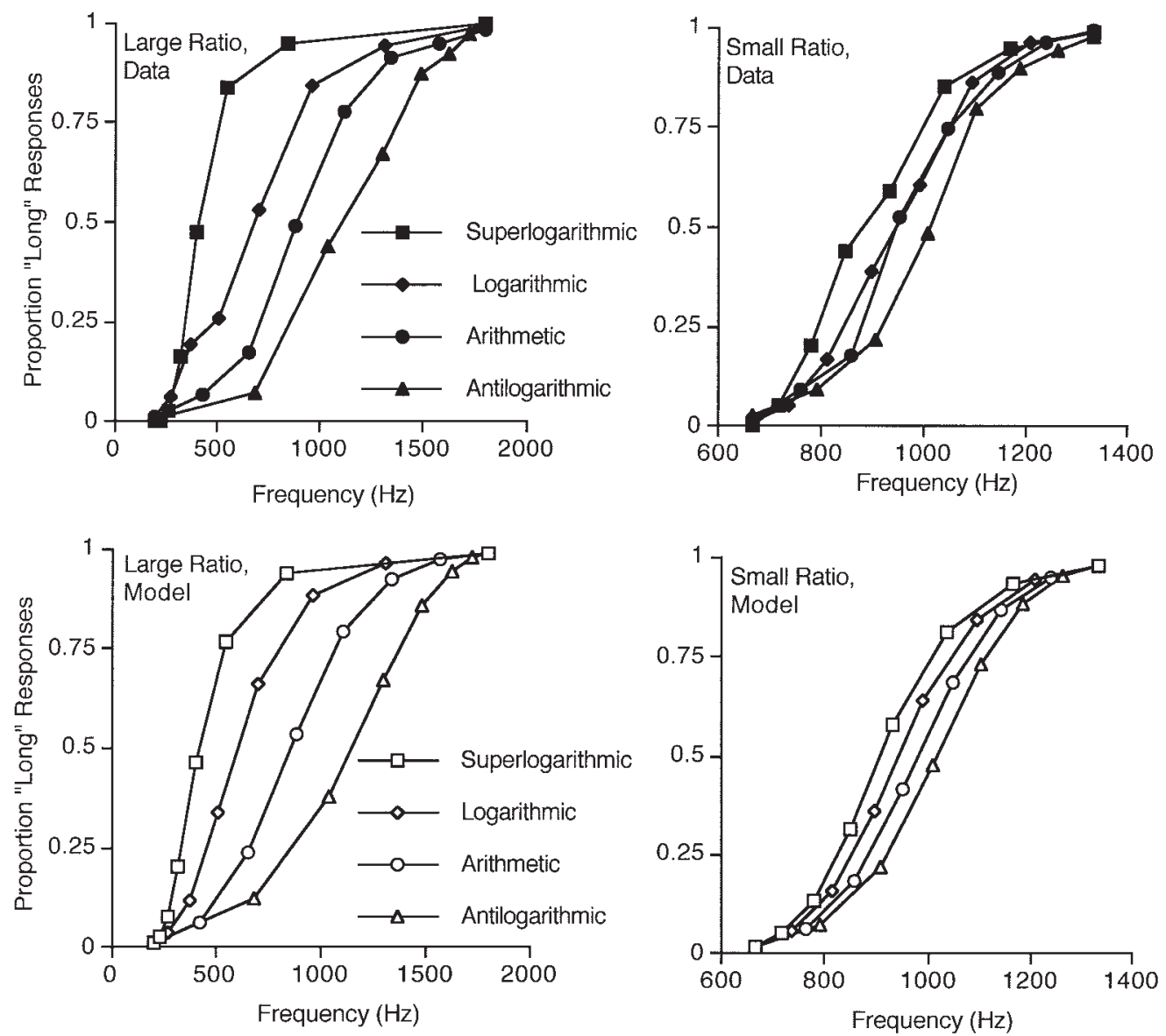

Figure 16. Observed frequency bisection curves (top row) and fit of the model to the data (bottom row).

Overall, the results of the frequency bisection task, as well as of the absolute identification task described earlier, were consistent with the hypothesis that similar principles may describe identification and bisection of tones varying in duration and tones varying in frequency. In particular, the temporal bisection point and the frequency bisection point varied in similar ways as a function of stimulus distribution and the ratio of the extreme stimuli, and the nature of these variations was well predicted by a model based on the principles of RFT.

\section{General Discussion}

We began this article with two key questions. The first question concerned the similarity between temporal and other dimensions. More specifically, is the identification and discrimination of short temporal durations similar to the identification and discrimination of other unidimensionally varying stimuli? The evidence that we have presented is consistent with an affirmative answer. In both absolute identification and bisection tasks, the key effects were qualitatively identical for temporal duration and for frequency and were consistent with previous results obtained using other dimensions. In absolute identification, similar bowed serial position curves were seen in both cases. Similar sequential effects (assimilation and contrast) were also observed. Finally, temporal bisection and frequency bisection appeared to follow similar principles.
In the previous literature, accounts of human-timing data have generally been developed independently within the temporal processing research literature. The results we have presented here suggest that it may be fruitful to examine whether older models that have already been developed in the psychophysical literature may be applicable to the domain of timing.

The second question with which we introduced the paper was more specific and concerned the shifts in temporal bisection point that have previously been observed in the literature. As we noted in the introduction, the temporal bisection point may fall close to the geometric mean, close to the arithmetic mean, or somewhere in between, with the observed result appearing to depend on factors such as (a) whether humans or animals are tested, (b) whether the stimuli are arithmetically or logarithmically spaced, and (c) whether the longest and shortest stimuli stand in a high or a low ratio to one another. However, as we noted in the introduction, the pattern of data is not entirely consistent. It seemed possible that RFT, a model independently developed in the magnitude estimation literature, might offer some general principles that would enable shifts in bisection point to be understood. More specifically, RFT and TRFT predict (with some auxiliary assumptions) that the bisection point for any unidimensionally varying stimuli, including temporal durations, should vary in predictable ways with the skew of the distribution of presented stimuli. Two experiments con- 


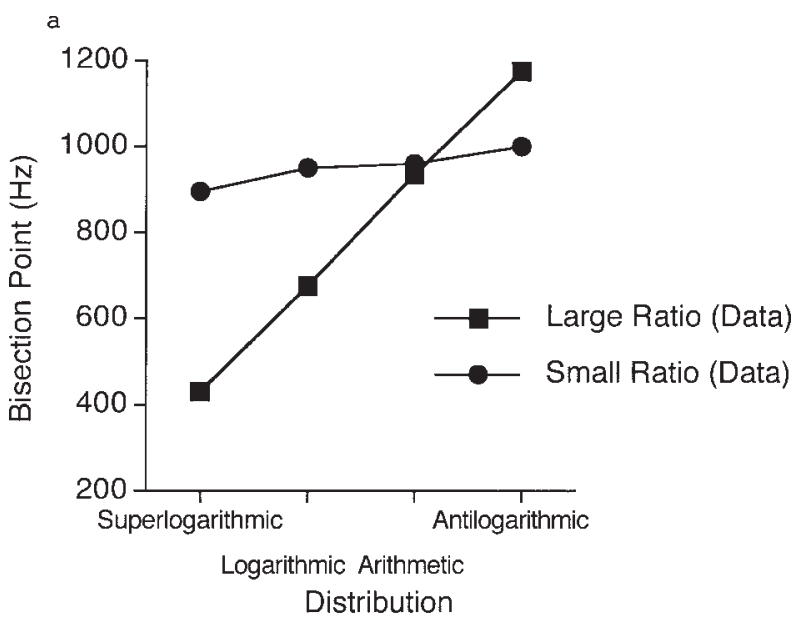

b

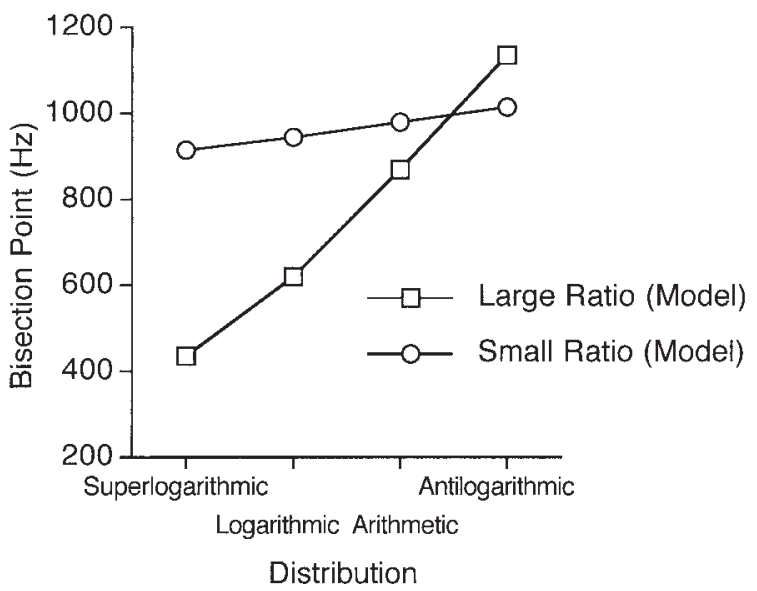

Figure 17. Observed (a) and predicted (b) frequency bisection points as a function of stimulus distribution and high:low ratio.

firmed these predictions for both a temporal bisection task and a frequency bisection task. The results are consistent with the claim that stimulus spacing may be important, particularly when the ratio of the longest to the shortest experimental duration is large (Allan, 2002b; Penney et al., 1998; Wearden \& Ferrara, 1995, 1996). More specifically, the results of the bisection task may offer an illustration of how older psychophysical models may be useful in interpreting the more recent temporal processing literature.

How does TRFT, and its account of contextual effects in timing, relate to the dominant model of timing, SET? Scalar expectancy theory is a detailed and widely applied model, driven by principles such as the scalar property and time-scale invariance. Furthermore, the parameters and components of SET's mathematical specification can be mapped onto a process-level interpretation in terms of mechanisms such as a pulse-generating clock, a comparator, and long-term and working memory representations of durations. TRFT, in contrast, is a descriptive model of how context influences the subjective judgment of durations. It is therefore more limited in scope than SET, and is neutral as to the underlying neurobiological mech- anisms that underpin duration perception. However a samplingbased account of how rank-dependent effects such as those assumed by TRFT may arise in magnitude judgment through ordinal comparison of a target stimulus with samples retrieved from memory is given by Stewart, Chater, and Brown (2005), and similar sampling mechanisms could potentially provide a process-based account of rank-dependent effects in duration perception. Furthermore, the parameters of TRFT can, like those of SET, each be given a psychological interpretation. The scaling parameter $c$ governs the rate at which the similarity between two durations decreases as their difference increases and is expected to increase with stimulus range. The $a$ parameter governs the form of the similarity-distance function (e.g., exponential, Gaussian, or intermediate) and is expected to increase as stimuli become more perceptually confusable. The $w$ parameter determines the degree to which the ranked position of a stimulus affects its subjective duration. Each of these parameters has been widely studied and interpreted outside the timing literature.

TRFT contrasts with SET and its relatives both in the account it gives of context effects and in basic assumptions such as the scalar property; we deal with each of these in turn. Context effects, although ubiquitous in experiments on perception of nontemporal magnitudes, have not been widely incorporated in SET-based models. Wearden and Ferrara (1995) approached stimulus spacing effects with a model in which participants in a temporal bisection task responded "long" or "short" according to whether a test duration was longer or shorter than the arithmetic mean of a stimulus set, while Wearden and Ferrara (1996) applied Wearden's (1991) modified difference model, according to which participants have a bias to respond "long" that comes into play whenever the difference between the test duration and the long standard and the difference between the test duration and the short standard are difficult to discriminate. The current account is clearly closer in spirit to the former account than the latter, because comparison of test durations to the arithmetic mean will naturally lead to spacing effects that qualitatively follow those observed here.

The memory-mixing model of duration bisection (e.g., Penney et al., 1998; see also Penney et al., 2000) could potentially account for context effects of the type emphasized in this article. The memory-mixing model assumes that test durations that are similar to the short or long standards contaminate the memory trace, particularly when the long:short ratio is large and the standards do not need to be remembered accurately for reasonable performance to result. This mechanism would lead to the short standard becoming represented in memory as longer than it is, and this will occur to a greater extent in more positively skewed distributions (the reverse will be the case for the memory of the long standard). Penney et al. (1998) show that such an approach may account for the observed differences between logarithmic and arithmetic spacing, and the same account could potentially be applied to the present results.

The account given by TRFT, while not denying that extant accounts could potentially be extended to account for the empirical effects described above, contrasts with previous models of context effects in that it imports a model independently developed and empirically successful outside the duration judgment literature and explicitly assumes that the same principles apply in both cases. 
A fundamental difference between TRFT and SET concerns the assumptions of the scalar nature of timing. The scalar assumption states that the coefficient of variation in timing is close to constant. TRFT has strong Weberian and scale-invariant properties, in that the confusability of two subjective durations will be a function of the ratio of the shorter to the longer if durations are represented on a logarithmic scale and generalization is exponential. However in temporal bisection tasks the scalar assumption is normally tested by superposition: If two temporal bisection curves superimpose when the probability of responding "long" is plotted as a function of test duration divided by bisection point, scalar timing is said to occur (Allan \& Gibbon, 1991). Several previous studies have indeed found good superposition under a wide range of conditions (e.g., Allan, 2002b; Allan \& Gerhardt, 2001; Allan \& Gibbon, 1991; Penney et al., 1998, 2000; Wearden \& Bray, 2001; Wearden \& Ferrara, 1996; Wearden et al., 1997), although small departures are sometimes observed (Penney et al., 1998, 2000; Wearden et al., 1997). However, TRFT makes the strong prediction that superposition of bisection curves obtained from different stimulus spacing need not occur, especially when the long:short ratio is large. TRFT predicts absence of superposition, even if stimulus range is held constant, because the subjective value of a given duration will depend on its context. For example, consider a set of durations ranging from $200 \mathrm{~ms}$ to $800 \mathrm{~ms}$. According to TRFT, a duration of $400 \mathrm{~ms}$ for example will be associated with a higher probability of responding "long" if it occurs in a positively skewed distribution than if it occurs in a negatively skewed distribution (range being held constant). Of course the bisection point will also be lower for the positively skewed distribution, and this will cause a tendency toward overlap of the bisection functions for the positively and negatively skewed distributions. However the location of the bisection point need not (except by coincidence) exactly cancel out the effects of stimulus skewing in such a way that superposition is obtained. The degree to which the probability of responding "long" will be elevated in the positively skewed distribution will be determined by its changed ranked position in the stimulus set, whereas the location of the bisection point will be determined by the precise values (i.e., not just the ranked position) of the other stimulus durations in the set. Thus the bisection point and the probability of responding "long" to a given item can vary with some degree of independence, and hence superposition need not occur.

To illustrate, we plotted superposition graphs to illustrate both the predictions of the model and the deviations from superposition obtained in the data. The top two panels of Figure 18 show the lack of superposition predicted by the model for
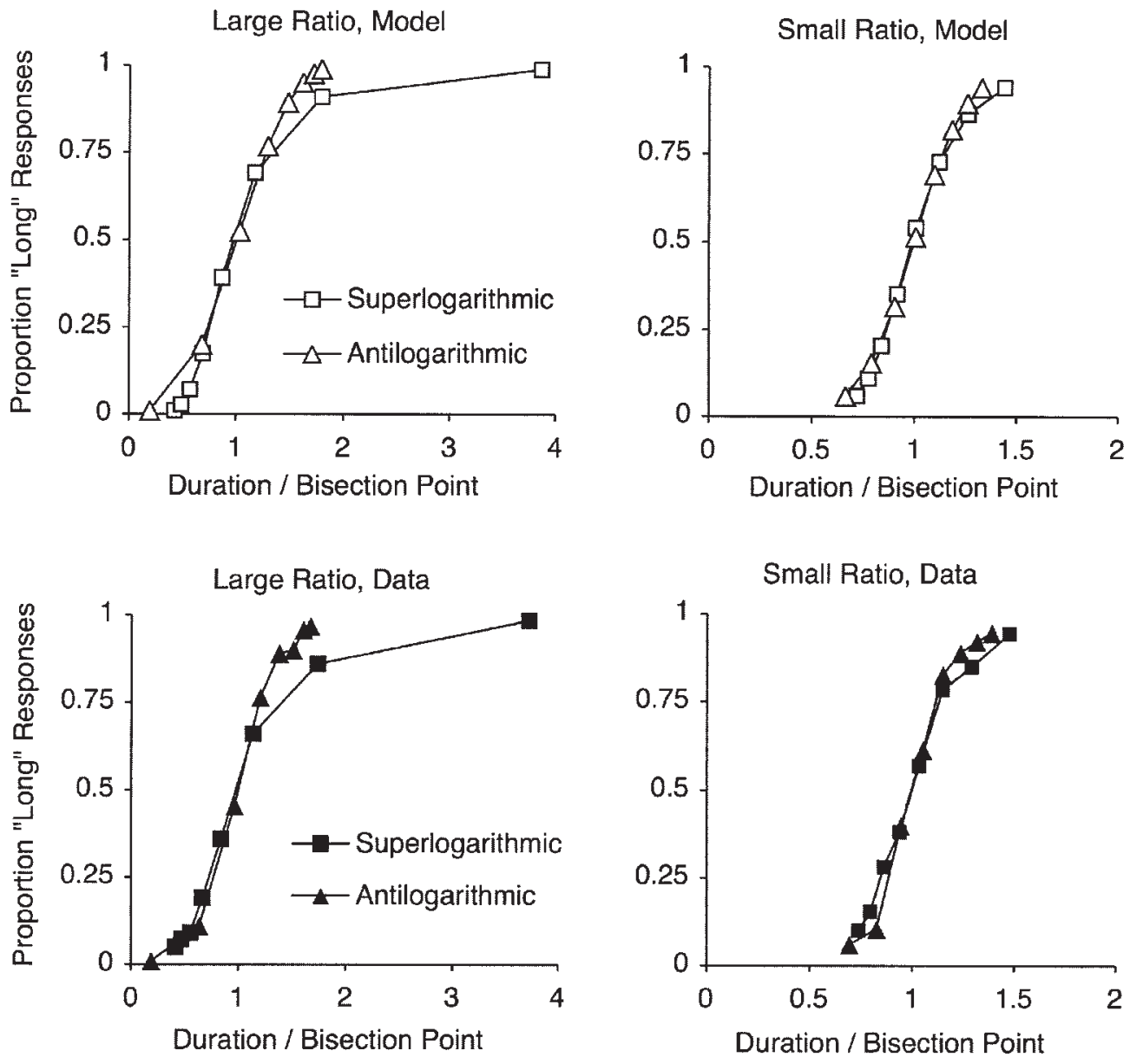

Figure 18. Predicted (top row) and observed (bottom row) bisection superposition graphs as a function of stimulus distribution and long:short ratio. 
both the large long:short ratio and the small long:short ratio cases. The bisection point for the model fit was used for the normalization, and model parameters were those previously used to fit the data. It is evident that a clear failure of superposition is predicted for the large-ratio stimulus set: The bisection curve for the more positively skewed (superlogarithmic) case is flatter than the curve for the most negatively skewed distribution (antilogarithmic). The superposed curves for the conditions of intermediate skew (logarithmic and arithmetic), while not shown, exhibit the expected intermediate pattern. A similar failure of superposition is observable in the small ratio set although the effect is much smaller in magnitude.

The lower two panels of Figure 18 show the equivalent normalized bisection curves observed in the data. It is evident that the predicted departure from superposition is indeed observed. Thus TRFT differs strongly from SET in predicting a failure of superposition, and the prediction is upheld empirically.

We note that the claim that TRFT principles may be relevant to judgment of temporal durations is a more general one than the specific hypotheses embodied in the model of bisection presented here. For example, a number of authors (e.g., Allan, 2002a; Allan \& Gerhardt, 2001; Wearden \& Ferrara, 1995) have suggested that participants may perform tasks such as temporal generalization and temporal bisection by comparing test tones to an implicit mean of some kind rather than reference to explicitly stored and remembered exemplars. Such an account could be consistent with TRFT principles, according to which the mean of the subjective magnitudes of positively skewed stimuli will be lower than the mean for negatively skewed stimuli even when the range is held constant (Parducci, 1968). For example, TRFT would predict that observed temporal bisection points will be lower for logarithmically spaced duration than for arithmetically spaced durations even if temporal bisection occurs through comparison of test durations to a single criterion such as the psychological mean or midpoint. Further research will be needed to evaluate the potential contribution of TRFT to paradigms outside adult temporal bisection.

\section{References}

Allan, L. G. (2002a). Are the referents remembered in temporal bisection? Learning and Motivation, 33, 10-31.

Allan, L. G. (2002b). The location and interpretation of the bisection point. Quarterly Journal of Experimental Psychology, 55(B), 43-60.

Allan, L. G., \& Gerhardt, K. (2001). Temporal bisection with trial referents. Perception \& Psychophysics, 63, 524-540.

Allan, L. G., \& Gibbon, J. (1991). Human bisection at the geometric mean. Learning and Motivation, 22, 39-58.

Berliner, J. E., \& Durlach, N. I. (1973). Intensity perception: IV. Resolution in roving-level discrimination. Journal of the Acoustical Society of America, 53, 1270-1287.

Block, R. A., \& Zakay, D. (1997). Prospective and retrospective duration judgments: A meta-analytic review. Psychonomic Bulletin \& Review, 4, 184-197.

Bower, G. H. (1971). Adaptation-level coding of stimuli and serial position effects. In M. H. Appley (Ed.), Adaptation-level theory (pp. 175-201). New York: Academic Press.

Braida, L. D., \& Durlach, N. I. (1972). Intensity perception: II. Resolution in one-interval paradigms. Journal of the Acoustical Society of America, 51, 483-502.

Brown, G. D. A., Neath, I., \& Chater, N. (2002). A ratio model of scale-invariant memory and identification. Manuscript submitted for publication.

Church, R. M., \& Deluty, M. Z. (1977). Bisection of temporal intervals. Journal of Experimental Psychology: Animal Behavior Processes, 3, $216-228$.

DeSoto, C. B., \& Bosley, J. G. (1962). The cognitive structure of a social structure. Journal of Abnormal and Social Psychology, 64, 303-307.

Dragoi, V., Staddon, J. E. R., Palmer, R. G., \& Buhusi, C. V. (2003). Interval timing as an emergent learning property. Psychological Review, 110, 126-144.

Droit-Volet, S., Clement, A., \& Fayol, M. (2003). Time and number discrimination in a bisection task with a sequence of stimuli: A developmental approach. Journal of Experimental Child Psychology, 84, 63-76.

Droit-Volet, S., \& Wearden, J. (2001). Temporal bisection in children. Journal of Experimental Child Psychology, 80, 142-159.

Droit-Volet, S., \& Wearden, J. (2002). Speeding up an internal clock in children? Effects of visual flicker on subjective duration. Quarterly Journal of Experimental Psychology, 55(B), 193-211.

Ebenholtz, S. M. (1963). Position mediated transfer between serial learning and a spatial discrimination task. Journal of Experimental Psychology, 65, 603-608.

Ennis, D. M. (1988). Confusable and discriminable stimuli: Comment on Nosofsky (1986) and Shepard (1986). Journal of Experimental Psychology: General, 117, 408-411.

Eriksen, C. W., \& Hake, H. W. (1957). Anchor effects in absolute judgments. Journal of Experimental Psychology, 53, 132-138.

Garner, W. R. (1953). An informational analysis of absolute judgments of loudness. Journal of Experimental Psychology, 46, 373-380.

Garner, W. R. (1962). Uncertainty and structure and psychological concepts. New York: Wiley.

Gautier, T., \& Droit-Volet, S. (2002). Attentional distraction and time perception in children. International Journal of Psychology, 37, 27-34

Gibbon, J. (1981). On the form and location of the psychometric bisection function for time. Journal of Mathematical Psychology, 24, 58-87.

Gibbon, J. (1986). The structure of subjective time: How time flies. Psychology of Learning and Motivation, 20, 105-135.

Gibbon, J., Church, R. M., \& Meck, W. H. (1984). Scalar timing in memory. In J. Gibbon \& L. G. Allan (Eds.), Timing and time perception (pp. 52-77). New York: New York Academy of Sciences.

Helson, H. (1964). Adaptation level theory. New York: Harper \& Row.

Holland, M. K., \& Lockhead, G. R. (1968). Sequential effects in absolute judgments of loudness. Perception \& Psychophysics, 3, 409-414.

Hu, G. (1997). Why is it difficult to learn absolute judgment tasks? Perceptual and Motor Skills, 84, 323-335.

Jensen, A. R. (1962). Temporal and spatial effects of serial position. American Journal of Psychology, 75, 390-400.

Jesteadt, W., Luce, R. D., \& Green, D. M. (1977). Sequential effects of the judgments of loudness. Journal of Experimental Psychology: Human Perception and Performance, 3, 92-104.

Killeen, P. R., \& Fetterman, J. G. (1988). A behavioral theory of timing. Psychological Review, 95, 274-295.

Killeen, P. R., \& Taylor, T. J. (2000). How the propagation of error through stochastic counters affects time discrimination and other psychophysical judgments. Psychological Review, 107, 430-459.

Krumhansl, C. L. (1978). Concerning the applicability of geometric models to similarity data: The interrelationship between similarity and spatial density. Psychological Review, 85, 445-463.

Lacouture, Y. (1997). Bow, range, and sequential effects in absolute identification: A response-time analysis. Psychological Research, 60, 121-133.

Lacouture, Y., Grondin, S., \& Mori, S. (2001). Absolute identification of temporal intervals: Preliminary data. In E. Sommerfeld, R. Kompass, \& T. Lachmann (Eds.), Proceedings of the Seventeenth Meeting of the 
International Society of Psychophysics (pp. 493-498). Berlin: Pabst Science Publishers.

Lacouture, Y., \& Marley, A. A. J. (1991). A connectionist model of choice and reaction time in absolute identification. Connection Science, 3, 401-433.

Lacouture, Y., \& Marley, A. A. J. (1995). A mapping model of the bow effects in absolute identification. Journal of Mathematical Psychology, 39, 383-395.

Laming, D. R. J. (1984). The relativity of "absolute" judgment. British Journal of Mathematical and Statistical Psychology, 37, 152-183.

Lockhead, G. R. (1984). Sequential predictors of choice in psychophysical tasks. In S. Kornblum \& J. Requin (Eds.), Preparatory states and processes (pp. 27-47). Hillsdale, NJ: Erlbaum.

Lockhead, G. R., \& King, M. C. (1983). A memory model of sequential effects in scaling tasks. Journal of Experimental Psychology: Human Perception and Performance, 9, 461-473.

Long, L. (1937). A study of the effect of preceding stimuli upon the judgment of auditory intensities. Archives of Psychology (New York), 30(No. 209).

Luce, R. D., Nosofsky, R. M., Green, D. M., \& Smith, A. F. (1982). The bow and sequential effects in absolute identification. Perception \& Psychophysics, 32, 397-408

Machado, A. (1997). Learning the temporal dynamics of behavior. Psychological Review, 104, 241-265.

Machado, A., \& Guilhardi, P. (2000). Shifts in the psychometric function and their implications for models of timing. Journal of Experimental Psychology: Animal Behavior Processes, 74, 35-54.

Machado, A., \& Keen, R. (1999). Learning to time (LeT) or scalar expectancy theory (SET)? A critical test of two models of timing. Psychological Science, 10, 285-290.

Machado, A., \& Keen, R. (2003). Temporal discrimination in a long operant chamber. Behavioural Processes, 62, 157-182.

McCormack, T., Brown, G. D. A., Maylor, E. A., Darby, R. J., \& Green, D. (1999). Developmental changes in time estimation: Comparing childhood and old age. Developmental Psychology, 35, 1143-1155.

McCormack, T., Brown, G. D. A., Maylor, E. A., Richardson, L. B. N., \& Darby, R. J. (2002). Effects of aging on absolute identification of duration. Psychology and Aging, 17, 363-378.

Miller, G. A. (1956). The magical number seven, plus or minus two: Some limits on our capacity for information processing. Psychological Review, 63, 81-97.

Murdock, B. B. (1960). The distinctiveness of stimuli. Psychological Review, 67, 16-31.

Nosofsky, R. M. (1983). Shifts of attention in the identification and discrimination of intensity. Perception \& Psychophysics, 33, 103-112.

Nosofsky, R. M. (1986). Attention, similarity, and the identificationcategorization relationship. Journal of Experimental Psychology: General, 115, 39-57.

Nosofsky, R. M. (1988). On exemplar-based exemplar representations: Reply to Ennis (1988). Journal of Experimental Psychology: General, 117, 412-414.

Nosofsky, R. M. (1997). An exemplar-based random-walk model of speeded categorization and absolute judgment. In A. A. J. Marley (Ed.), Choice, decision, and measurement (pp. 347-365). Hillsdale, NJ: Erlbaum.

Parducci, A. (1965). Category judgment: A range-frequency model. Psychological Review, 72, 407-418.

Parducci, A. (1968, December). The relativism of absolute judgment. Scientific American, 219, 84-90.

Parducci, A. (1995). Happiness, pleasure, and judgment: The contextual theory and its applications. Mahwah, NJ: Erlbaum.

Penney, T. B., Allan, L. G., Meck, W. H., \& Gibbon, J. (1998). Memory mixing in duration bisection. In D. A. Rosenbaum \& C. E. Collyer (Eds.), Timing of behavior: Neural, computational, and psychological perspectives (pp. 165-193). Cambridge, MA: MIT Press.
Penney, T. B., Gibbon, J., \& Meck, W. H. (2000). Differential effects of auditory and visual signals on clock speed and temporal memory. Journal of Experimental Psychology: Human Perception and Performance, 26, 1770-1787.

Platt, J. R., \& Davis, E. R. (1983). Bisection of temporal intervals by pigeons. Journal of Experimental Psychology: Animal Behavior Processes, 9, 160-170.

Pollack, I. (1952). The information of elementary auditory displays. Journal of the Acoustical Society of America, 24, 745-749.

Pollio, H. R., \& Deitchman, R. (1964). The activational characteristics of a serial cognitive structure having oppositional end points. Unpublished manuscript, University of Tennessee.

Purks, S. R., Callahan, D. J., Braida, L. D., \& Durlach, N. I. (1980). Intensity perception: $\mathrm{X}$. Effect of preceding stimulus on identification performance. Journal of the Acoustical Society of America, 67, 634637.

Raslear, T. G. (1983). A test of the Pfanzagl bisection model in rats. Journal of Experimental Psychology: Animal Behavior Processes, 9, $49-62$.

Raslear, T. G. (1985). Perceptual bias and response bias in temporal bisection. Perception \& Psychophysics, 38, 261-268.

Rattat, A. C., \& Droit-Volet, S. (2001). Variability in 5- and 8-year-olds' memory for duration: An interfering task in temporal bisection. Behavioural Processes, 55, 81-91.

Rodriguez-Girones, M., \& Kacelnik, A. (2001). Relative importance of perceptual and mnemonic variance in human temporal bisection, Quarterly Journal of Experimental Psychology, 54(A), 527-546.

Shepard, R. N. (1987a). Time and distance in generalization and discrimination: Reply to Ennis (1988). Journal of Experimental Psychology: General, 117, 415-416.

Shepard, R. N. (1987b, September 11). Toward a universal law of generalization for psychological science. Science, 237, 1317-1323.

Siegel, S. F. (1986). A test of the similarity rule model of temporal bisection. Learning and Motivation, 17, 59-75.

Siegel, S. F., \& Church, R. M. (1984). The decision rule in temporal bisection. Annals of the New York Academy of Sciences, 423, 643-645.

Staddon, J. E. R., \& Higa, J. J. (1999). Time and memory: Towards a pacemaker-free theory of interval timing. Journal of the Experimental Analysis of Behavior, 71, 215-251.

Staddon, J. E. R., King, M., \& Lockhead, G. R. (1980). On sequential effects in absolute judgment experiments. Journal of Experimental Psychology: Human Perception and Performance, 6, 290-301.

Stevens, S. S. (1975). Psychophysics. New York: Wiley.

Stewart, N., Brown, G. D. A., \& Chater, N. (in press). Absolute identification by relative judgment. Psychological Review.

Stewart, N., Chater, N., \& Brown, G. D. A. (2005). Decision by sampling. Manuscript submitted for publication.

Treisman, M. (1985). The magical number seven and some other features of category scaling: Properties for a model of absolute judgment. Journal of Mathematical Psychology, 29, 175-230.

Treisman, M., \& Williams, T. C. (1984). A theory of criterion setting with an application to sequential dependencies. Psychological Review, 91, 68-111.

Volkmann, J. (1951). Scales of judgment and their implications for social psychology. In J. H. Rohrer and M. Sherif (Eds.), Social psychology at the crossroads (pp. 279-294). New York: Harper \& Row.

Ward, L. M., \& Lockhead, G. R. (1970). Sequential effects and memory in category judgment. Journal of Experimental Psychology, 84, 27-34.

Ward, L. M., \& Lockhead, G. R. (1971). Response system processes in absolute judgment. Perception \& Psychophysics, 9, 73-78.

Wearden, J. H. (1991). Human performance on an analogue of the interval bisection task. Quarterly Journal of Experimental Psychology, 43(B), $59-81$.

Wearden, J. H. (1992). Temporal generalization in humans. Journal of Experimental Psychology: Animal Behavior Processes, 18, 134-144. 
Wearden, J. H. (1995). Categorical scaling of stimulus duration by humans. Journal of Experimental Psychology: Animal Behavioral Processes, 21, 318-330.

Wearden, J. H., \& Bray, S. (2001). Scalar timing without reference memory? Episodic temporal generalization and bisection in humans. Quarterly Journal of Experimental Psychology, 54(B), 289-309.

Wearden, J. H., \& Ferrara, A. (1995). Stimulus spacing effects in temporal bisection by humans. Quarterly Journal of Experimental Psychology, 48(B), 289-310

Wearden, J. H., \& Ferrara, A. (1996). Stimulus range effects in temporal bisection by humans. Quarterly Journal of Experimental Psychology, 49(B), 24-44.

Wearden, J. H., Rogers, P., \& Thomas, R. (1997). Temporal bisection in humans with longer stimulus durations. Quarterly Journal of Experimental Psychology, 50(B), 79-94.

Received January 7, 2004 Revision received October 29, 2004

Accepted March 9, 2005

\section{American Psychological Association SUBSCRIPTION Claims INFORMATION}

Today's Date:

We provide this form to assist members, institutions, and nonmember individuals with any subscription problems. With the appropriate information we can begin a resolution. If you use the services of an agent, please do NOT duplicate claims through them and directly to us. PLEASE PRINT CLEARLY AND IN INK IF POSSIBLE.

\begin{tabular}{l}
\hline PRINT FULL NAME OR KEY NAME OF INSTITUTION \\
\hline ADDRESS \\
\hline CITY \\
STATE/COUNTRY
\end{tabular}

YOUR NAME AND PHONE NUMBER

TITLE
MEMBER OR CUSTOMER NUMBER (MAY BEFOUND ON ANY PAST ISSUE LABEL)

DATE YOUR ORDER WAS MAILED (OR PHONED)

__ PREPAID _ CHECK _ CHARGE CHECK/CARD CLEARED DATE:

(If possible, send a copy, front and back, of your cancelled check to help us in our research of your clainn.)

ISSUES: MISSING DAMAGED
NUMBER OR MONTH

Thank you. Once a claim is received and resolved, delivery of replacement issues routinely takes 4-6 weeks.

(TO BE FILLED OUT BY APA STAFF)

DATE RECEIVED:

ACTION TAKEN:

STAFF NAME:
DATE OF ACTION:

INV. NO. \& DATE:

LABEL NO. \& DATE:

Send this form to APA Subscription Claims, 750 First Street, NE, Washington, DC 20002-4242

PLEASE DO NOT REMOVE. A PHOTOCOPY MAY BE USED. 